\title{
Article
}

\section{Clathrin-mediated endocytic uptake of PUFA enriched self-nanoemulsifying lipidic systems (SNELS) of an anticancer drug against triple negative cancer and DMBA induced preclinical tumor model}

Khurana, Rajneet Kaur, Kumar, Rajendra, Gaspar, Balan Louis, Welsby, Gail, Welsby, Philip John, Kesharwani, Prashant, Katare, O.P, Singh, Kamalinder and Singh, Bhupinder

Available at http://clok.uclan.ac.uk/23451/

Khurana, Rajneet Kaur, Kumar, Rajendra, Gaspar, Balan Louis, Welsby, Gail, Welsby, Philip John ORCID: 0000-0002-2110-8198, Kesharwani, Prashant, Katare, O.P, Singh, Kamalinder ORCID: 0000-0001-7325-0711 and Singh, Bhupinder (2018) Clathrin-mediated endocytic uptake of PUFA enriched selfnanoemulsifying lipidic systems (SNELS) of an anticancer drug against triple negative cancer and DMBA induced preclinical tumor model. Materials Science \& Engineering C, 91 . pp. 645-658. ISSN 0928-4931

It is advisable to refer to the publisher's version if you intend to cite from the work. http://dx.doi.org/10.1016/j.msec.2018.05.010

For more information about UCLan's research in this area go to http://www.uclan.ac.uk/researchgroups/ and search for < name of research Group>.

For information about Research generally at UCLan please go to http://www.uclan.ac.uk/research/

All outputs in CLoK are protected by Intellectual Property Rights law, including Copyright law. Copyright, IPR and Moral Rights for the works on this site are retained by the individual authors and/or other copyright owners. Terms and conditions for use of this material are defined in the policies page. 
Clathrin-mediated endocytic uptake of PUFA mediated self-nanoemulsifying lipidic systems (SNELS) of an anticancer drug against triple negative cancer and DMBA induced preclinical tumor model

\author{
Rajneet Kaur Khurana ${ }^{1}$, Rajendra Kumar², Balan Louis Gaspar ${ }^{3}$, Gail Welsby ${ }^{4}$, Philip \\ Welsby $^{4}$, Prashant Kesharwani ${ }^{5,6}$, OP Katare ${ }^{1}$, Kamalinder K Singh, ${ }^{4 *}$ Bhupinder \\ Singh ${ }^{1,2 *}$ \\ ${ }^{1}$ University Institute of Pharmaceutical Sciences, UGC Centre of Advanced Studies, \\ Panjab University, Chandigarh 160014, India \\ ${ }^{2} U G C$-Centre of Excellence in Applications of Nanomaterials, Nanoparticles and \\ Nanocomposites (Biomedical Sciences), Panjab University, Chandigarh 160014, India \\ ${ }^{3}$ Department of Histopathology, Post Graduate Institute of Medical Education and Research, \\ Chandigarh 160012, India \\ ${ }^{4}$ School of Pharmacy and Biomedical Sciences, Faculty of Clinical and Biomedical Sciences \\ University of Central Lancashire, Preston PR $12 \mathrm{HE}, \mathrm{UK}$ \\ ${ }^{5}$ Department of Pharmaceutical Technology, International Medical University, \\ Bukit Jalil Kuala Lumpur, Malaysia \\ ${ }^{6}$ Pharmaceutics Division, CSIR-Central Drug Research Institute, Lucknow, UP, 226031 \\ India
}

*To whom correspondence should be addressed

Professor Bhupinder Singh Bhoop

University Institute of Pharmaceutical Sciences

Coordinator, UGC Center for Excellence in Nano Applications

Panjab University, Chandigarh 160 014, India

E-mail: bsbhoop@yahoo.com, bsbhoop@pu.ac.in

Professor Kamalinder K. Singh

School of Pharmacy and Biomedical Sciences,

Faculty of Clinical and Biomedical Sciences

University of Central Lancashire,

Preston, PR1 2HE, United Kingdom

Email: ksingh1@uclan.ac.uk; profkksingh@gmail.com 


\section{ABSTRACT}

The current studies envisage unravelling the underlying cellular internalisation mechanism of the systematically developed docetaxel (DTH) polyunsaturated fatty acid (PUFA) enriched self-nanoemulsifying lipidic micellar systems (SNELS). The concentration-, time- and cytotoxicity-related effects of DTH-SNELS on triple negative breast cancer (TNBC) MDAMB-231 and non-TNBC MCF-7 cell lines were assessed through Presto-blue assay. Subsequently, rhodamine-123 (Rh-123) loaded SNELS were employed for evaluating their internalisation through flow cytometry and fluorescence microscopy, establishing it to be "clathrin-mediated" endocytic pathway. Apoptosis assay (65\% cell death) and cell cycle distribution (47\% inhibition at G2/M phase) further corroborated the cytotoxicity of DTHSNELS towards cancerous cells. Biodistribution, histopathology and haematology studies indicated insignificant toxicity of the optimized formulation on vital organs. Preclinical anticancer efficacy studies using 7,12-dimethylbenzantracene (DMBA)-induced model construed significant reduction in breast tumor-volume. Overall, extensive in vitro and in vivo studies indicated the intracellular localization and cytotoxicity, suggesting DTH-SNELS as promising delivery systems for breast tumour therapeutics including TNBC.

Keywords: Breast cancer; triple negative breast cancer (TNBC); Poly unsaturated fatty acid (PUFA); self-nanoemulsifying drug delivery systems; clathrin mediated endocytosis apoptosis. 


\section{Background}

Breast cancer is one of the most commonly diagnosed carcinoma in women throughout the world. Among the subtype of breast cancers, triple negative breast cancer (TNBC) which are tumours that do not express oestrogen, progesterone and human epidermal growth factor receptors, account for almost $20 \%$ of breast cancers (Bauer et al., 2007). Since TNBC does not have the receptors for hormones, they do not benefit from treatment with hormonal therapy and treatment options are limited to chemotherapy and radiotherapy (Kalimutho et al, 2015). However being clinically aggressive type of cancer its responsiveness to chemotherapy is very poor (Marotti et al., 2017). Treating this type of cancer presents a major challenge due to the poor disease prognosis and therefore the need for newer and safer therapies.

The first-line drug currently employed for the management of breast cancer belongs to the group of semi-synthetic taxanes, i.e., docetaxel (DTH), being marketed as intravenous preparation, namely Taxotere ${ }^{\circledR}$ and Docefrez ${ }^{\circledR}$. DTH, an antimitotic chemotherapeutic drug, promotes the assembly of tubulins into microtubulins, stabilizes microtubules, and thus inhibits cell proliferation (Stanton et al., 2011). The clinical applications of DTH are hampered by severe side effects such as neutropenia, anaemia, febrile neutropenia, hypersensitivity, thrombocytopenia, peripheral neuropathy, musculoskeletal toxicity and hypersensitivity (Montero et al., 2005). Besides, DTH, being a biological classification systems (BCS) Class II drug, encounters several physico-chemical challenges, i.e., practically insoluble in water with quite high $\log \mathrm{P}$ of 2.9 , poor oral bioavailability (8\%) coupled with high hepatic first-pass metabolism and significant efflux by permeability glycoprotein (P-gp) transporter systems leading to multi-drug resistance (Khurana et al., 2016).

Polyunsaturated fatty acids (PUFA)-based drug delivery systems have been increasingly 
investigated for improved bioavailability owing to the enhanced oral drug absorption (Sandhu et al., 2017). Studies have shown improvement in anticancer eficacy of chemotherapeutic drugs when administered along with PUFA(). Further their advantage in breast cancer therapeutics in prevention of metastatic growth has been recogonised (Bougnoux et al., 2010). Our previous study demonstrated significant improvement in the biopharmaceutical attributes of DTH, when formulated as self-nanoemulsifying lipidic system (SNELS) containing PUFA-rich lipid with long chain omega-6 and omega-9 fatty acids. PUFA SNELS solubilised DTH due to micellization leading to augumented bioavailability with absorption through lymphatic pathways (Khurana et al., 2017 (a)).

Present study further investigates the potential of PUFA lipid rich SNELS of DTH.in breast cancer therapeutics. DTH-SNELS was evaluated for its efficacy in two different mammary human adenocarcinoma cells, MCF-7 and MDA-MB-231. While MCF-7, molecularly classified as Luminal A exhibiting ER+/PR+/HER2- receptors, MDA-MB-231 are more aggressive TNBC cell lines not exhibiting ER-/PR-/HER2-receptors (Wiggins et al., 2015). In the current research article, the major emphasis has been laid on exploring cellular internalisation and its underlying mechanisms which has never been investigated in both TNBC and non-TNBC cells for SNELS till date. In addition, mechanism of DTH action has also been elucidated through cell cycle analysis and apoptosis assay. The MDR reversal assay using rhodamine 123 (RH-123) and DiOC2 dye has been used to investigate the inhibitory activity of DTH-SNELS on MDR1 and BCRP transporters, respectively. Toxicity of DTHSNELS has been evaluated through biodistribution of drug, histopathology of the excised vital organs and haematology studies. Further preclinical in vivo tumour efficacy has been established in 7,12-dimethylbenzantracene (DMBA)-induced tumor model. The results of our research provide valuable evidence, which supports the development of DTH-SNELS for 
improved breast cancer therapeutics especially triple negative breast cancer which is known for its poor prognosis (Joyce 2017).

\section{Methods}

\subsection{Preparation of DTH-SNELS}

The optimal composition of DTH-SNELS was systematically derived using QbD approach employing PUFA rich lipid Maisine-35-1, which is a blend of partially digested long-chain glycerides: $33.5 \%$ monoglycerides, 50.9\% diglycerides, and $14.7 \%$ triglycerides, predominantly of linoleic acid (51.1\%, omega 6 C18:2) and oleic acid (32.8\%, omega 9 C18:1) was employed to fabricate the DTH-SNELS. Tween 80 and Transcutol HP were used as surfactant and co-surfactant respectively. The brief on its development, characterization and evaluation studies has been mentioned under "Supplementary-Section (1)". Briefly, 20 mg of DTH was added to glass vial containing the mixture of PUFA-enriched Maisine-35-1 (338 mg), Tween 80 (434 mg) and Transcutol HP (227 mg), followed by vortexing for $2 \mathrm{~min}$ to obtain a homogenous mixture. The resultant mixture was allowed to incubate in shaker water bath (Lab Tech, Korea) operated at 50 strokes/min for $24 \mathrm{~h}$ at $37^{\circ} \mathrm{C}$ to attain the equilibrium and form an isotropic formulation of liquid DTH-SNELS. DTH-SNELS were analysed for self-emulsification time, globule size, zeta potential and drug loading as per standard protocols provided in "Supplementary-Section (2)".

\subsection{MCF-7 and MDA-MB-231 Cell Culture Experiments}

The details on the cell line procurement, cell culture experiments and conditions have been elaborated in "Supplementary-Section (3)".

\subsubsection{Cell Viability Assay}

The cytotoxicity of DTH, blank SNELS and DTH-SNELS was assessed on MCF-7 and MDA-MB-231 cells using PrestoBlue (Invitrogen, USA). Details on the experimental technique have been mentioned in "Supplementary-Section (3.1)". 


\subsubsection{Qualitative and Quantitative Cellular uptake}

Qualitative cellular uptake investigations were conducted by fluorescence microscopy on MCF-7 and MDA-MB-231 cell lines employing rhodamine-123 (Rh-123) as a tracker dye, loaded on DTH-SNELS. Cells $\left(1 \times 10^{5}\right)$ per well for both cell lines were plated in 6-well plate containing cover-slips, and allowed to adhere for an overnight (Lin Mei, 2009, Khurana et al., 2018). Once adhered, the cells were treated with $0.078 \mu \mathrm{M}$ loaded Rh-123 DTH-SNELS (Rh123-DTH-SNELS) $(50 \mu \mathrm{g})$ for $15 \mathrm{~min}$ to $4 \mathrm{~h}$ separately at $37^{\circ} \mathrm{C}$. Subsequently, the cells were washed thrice with pre-warmed PBS and fixed for 20min at room temperature using 4\% (v/v) paraformaldehyde. Cells were washed thrice with PBS prior to mounting these on the microscope slides with Vectashield ${ }^{\circledR}$ mounting medium containing 300nM DAPI for staining the cell nuclei. Cells were imaged on a modified Zeiss Cell Observer Imaging System using a Zeiss EC-Plan-Neofluar 40x/1.3 oil objective, while Rh-123 and DAPI were imaged using a filter set with Ex/Em of 450-490nm/500-550nm and 335-383nm/420-470nm, respectively and analysed using the Zeiss ZEN desk Imaging Software. For quantitative measurement, $1 \times 10^{5}$ cells were seeded in each well of the six-well plate and incubated for an overnight. Rh123-SNELS $(100 \mu \mathrm{g} / \mathrm{mL})$ was added to each well and cells were incubated for different time intervals, in a manner quite similar to qualitative measurement. The medium containing SNELS was removed after respective time point, cells were tyrpsinized after intense washing and re-suspended in PBS for immediate Flowcytometry analysis. Rh-123 signals were detected in FL-1 channel $(530 / 30 \mathrm{~nm})$ of BD-FACSAria flow cytometer. A total of 10,000 events were acquired and data were analysed using Flowing software version 2.5.1 (University of Turko, Finland).

\subsubsection{Mechanism of Cellular Uptake}

To confirm the mechanism of cellular uptake, specific pharmacological inhibitors were used while cell number and culture conditions were similar to those employed during 
cellular uptake experiments (Martins S, 2012). Briefly, sucrose $(0.45 \mathrm{M})$ for clathrindependent, nystatin $(5 \mu \mathrm{g} / \mathrm{mL})$ for caveolae-dependent, and cytochalasin-B $(5 \mu \mathrm{g} / \mathrm{mL})$ for phagocytosis-dependent were used. After $30 \mathrm{~min}$ of respective inhibitor treatment, cells were further exposed to Rh-123-DTH-SNELS for $30 \mathrm{~min}$. Cells were incubated at $4^{\circ} \mathrm{C}$ instead of $37^{\circ} \mathrm{C}$, in order to inhibit the endocytosis process, washed with warm PBS, and counter stained with DAPI for fluorescent microscopy. Trypsinized cells from separate plates were used for flowcytometric based measurement.

\subsubsection{Cell Death Assay}

To study the mechanism of cell death, Annexin-propidium iodide (PI) assay was used. Briefly, 1x105 MCF-7 and MDA-MB-231 cells were seeded in each well of 24-well plate and allowed to adhere for an overnight (Morse et al., 2005). Cells were treated with DTH, blank SNELS and DTH-SNELS for 24h. After incubation, the cells were harvested using trypsin and washed with PBS. Cell pellet was reconstituted in annexin binding buffer $(100 \mu \mathrm{L})$ and stained as per the manufacturer's instructions (Molecular Probes Inc, Oregon USA). Untreated cells, serving as control, were used to set the quadrant in dotplot. Stained cells were acquired immediately using benchtop flowcytometer (Acuri C6, BD, US BD Biosciences, CA USA). A total of 10,000 cells per treatment were acquired from 3 independent experiments.

\subsubsection{Cell Cycle Analysis}

To study the effect of free drug and DTH-SNELS on distribution of cells in different phases, PI cell cycle analysis was conducted (Pozarowski P, 2004). Cells (1x10 per well) were seeded in 24-well plate, incubated for an overnight and treated with $\mathrm{IC}_{50}$ dose of the drug and SNELS containing an equivalent amount. Post-treatment, cells were de-adhered using trypsin and washed with PBS. Re-dispersed cells were fixed using 70\% ice-chilled ethanol, added drop-wise and stored at $-20^{\circ} \mathrm{C}$ at least for $24 \mathrm{~h}$. Fixed cells were stained with 
$50 \mu \mathrm{g} / \mathrm{mL}$ of PI (Sigma Aldrich, UK) in the presence of $100 \mu \mathrm{g} / \mathrm{mL}$ RNAse (Sigma, USA) at $37^{\circ} \mathrm{C}$ for $30 \mathrm{~min}$. Stained nuclei were analysed on BD-FACSAria flowcytometer (BD Biosciences, CA, USA) (Cecchini et al., 2012).

\subsubsection{P-gp efflux assay}

Overexpression of P-gp on MCF-7 and MDA-MB-231 cells is well documented in literature (He et al., 2010; Bao et al., 2012). P-gp confers resistance by preventing enough accumulation of anticancer drugs within the cell, thereby avoiding their cytotoxic or apoptotic effects (Liang et al., 2010). For evaluating the P-gp efflux, the multi-drug resistance dye efflux assay kit (M/s Chemicon International, USA) was employed, the detailed procedure is mentioned in Section 3.2.

\subsubsection{Cellular Uptake by Macrophages}

RAW 264.7, mouse monocyte macrophage was procured from ECACC, Public Health England, Salisbury, England. To understand the macrophage uptake, $1 \times 10^{5}$ cells/well were seeded in DMEM media supplemented with FBS and glutamine, incubated in 6-well culture plate for overnight. These cells were treated with Rh-123-DTH-SNELS for $4 \mathrm{~h}$ and were analyzed as per the procedure described in Section 2.2.2 for qualitative and quantitative analysis. Intensity of the fluorescence indicated the extent of cellular uptake.

\subsection{In Vivo Studies}

\subsubsection{Toxicity study}

The short-term repeated dose toxicity studies were performed as per the guidelines of Organization Economic Cooperation and Development (OECD; TG 407). The animals were procured from Panjab University Centre Animal House, after obtaining the requisite approval from Animals Institutional Committee, Chandigarh (PU/IAEC/S/14/104). Details of the 
experimental details on histopathological, haematological and biodistribution studies are mentioned under "Supplementary-Section 4".

\subsubsection{In vivo antitumor efficacy}

In vivo antitumor efficacy was evaluated in DMBA induced breast cancer model in female Wistar rats (weighing 200-225g) (Wang and Zhang, 2017). Mammary tumor was induced by administration of DMBA solution in soybean oil $\mathrm{i} / \mathrm{p}$ at a dose of $45 \mathrm{mg} / \mathrm{kg}$ at weekly intervals for 3 weeks. When tumor reached measurable size, all the tumor-bearing animals were segregated and divided into 3 groups, i.e., free DTH (20mg/kg), DTH-SNELS (equivalent to $20 \mathrm{mg} / \mathrm{kg} \mathrm{DTH}$ ) and normal saline. Length of the tumour was measured using vernier calliper, and tumor volume (V) was measured according to the following formula $(\mathrm{Eq}-1)$ :

$V=\frac{4}{3} \pi r^{3}$ ..... Eq 1

where, $r$ is the radius of the tumor. All the animals were weighed and tumor size was recorded prior to treatment. The treatments were administered thrice a week for a total of 4week period, and tumor growth was monitored for 30 days. Tumor size and animal weight were measured over a period of 60 days and animals were observed for any sign(s) of mortality (Athawale et al., 2014).

\section{Results}

\subsection{Self-emulsification time}

Emulsification time of DTH-SNELS in $0.1 \mathrm{~N} \mathrm{HCl}(\mathrm{pH} \mathrm{1.2)} \mathrm{was} \mathrm{found} \mathrm{to} \mathrm{range}$ between 130 and 190 seconds, i.e., < 3min. Lower values of emulsification in the current study indicated the spontaneity of the emulsification process of the DTH-SNELS to produce the nanoemulsion with transparent bluish tinge appearance (Beg et al., 2013). 


\subsection{Globule size and zeta potential}

DTH-SNELS showed globule size of $<115 \mathrm{~nm}$ indicating its nano-micelllar nature while zeta potential of $-30 \mathrm{mV}$ confirmed its stability (Beg et al., 2013).

\subsection{Cell Viability Assay}

The concentration and time-dependent cytotoxicity of DTH, blank SNELS and DTHSNELS was investigated for MCF-7 and MDA-MB-231 cell lines using Presto blue cell viability assay (Figure 1). DTH-SNELS exhibited an early onset of action in MCF-7 cells as compared to MDA-MB-231 (Figure 1). The $\mathrm{IC}_{50}$ value for MCF-7 cells was 4.7, 5.96, 8.68 folds and for MDA-MB-231 cells 1.87, 2.09, 3.35 fold higher than DTH at 24, 48 and 72h respectively, clearly demonstrating superior cytotoxic performance of DTH-SNELS in both type of cells. From our results it was delineated, DTH is less effective for TNBC cells than the other breast cancer cell lines. It is noteworthy that the DTH-SNELS showed higher cytotoxicity as compared to the free drug not only for MCF-7 but as well as for TNBC MDAMB-231 cells. TNBC being more aggressive is the difficult type of cancer to cure and has higher rate of recurrence as compared to other types of breast cancers (Ovcaricek et al., 2011). DTH-SNELS showed promise with required low drug concentration in order to achieve the same in vitro therapeutic efficiency, than free DTH for MDA-MB-231. This could be due to the advantages of nanomedicine, including the high drug transportation efficiency across the cell membrane by the mechanism of endocytosis, and also the ability of the nanocarrier to overcome multi-drug resistance (MDR).

\subsection{Qualitative and Quantitative Cellular Uptake}

For investigating the cellular uptake in MCF-7 and MDA-MB-231 cells, it has been observed that Rh-123-DTH-SNELS started appearing within first 10 min in MCF-7 and 30 min in MDA-MB-231 cells as visualized by the presence of green signals mostly localized around the nuclei in the cytoplasm [Figure 2 (A) and (D)]. Qualitative analysis using 
photomicrographs displayed the fluorescent signals due to Rh-123-DTH-SNELS uptake at various time points in MCF-7 [Figure 2(A)] and MDA-MB-231 cells [Figure 2(D)]. The corresponding overlay histograms generated after the data were analysed through flowing software, further corroborated the substantial cellular uptake of SNELS at the given time points, i.e., 30min, $2 \mathrm{~h}$ and $4 \mathrm{~h}$ in both TNBC [Figure 2(E)] and non-TNBC cells [Figure 2(B)], though the intensity of fluorescence was more for MCF-7 cells than MDA-MB-231 cells suggesting that the SNELS encountered less hindrance with MCF-7 cells. The results are contradictory to some of reports documented in literature where MDA-MB-231 cells seems to be more sensitive (Reddel et al., 1985; Jia et al., 2014).

Further quantitative analysis made through the FITC value generated for various timepoints supported the increase of its value upto $4 \mathrm{~h}$. Interestingly, it was observed that there was no increase in FITC fluorescence value after $4 \mathrm{~h}$, in both the cell lines [Figure 2(C) \& (F)]. Fluorescence signals were recorded upto $24 \mathrm{~h}$ exposure (data not shown) proposing that $1 \times 10^{5}$ concentration of cells were getting saturated with the micelles formed from $100 \mu \mathrm{g}$ of Rh-123-DTH-SNELS, with no further increase in the FITC value observed after 4h. Literature also supports the saturation effect of cells after a certain period (Garanti et al., 2016). After 30min, the faster cellular uptake was observed for MCF-7, as depicted from higher FITC value, than for MDA-MB-231 cells.

\subsection{Cellular Uptake Mechanisms}

Mechanistic insights to investigate the uptake mechanisms were provided by both qualitative and quantitative measurement. Figure 3 (A\&C), displays histograms of flow cytometry and their corresponding fluorescent images, delineating that the prime pathway of SNELS uptake for both MCF-7 and MDA-MB-231 cell lines to be clathrin-mediated endocytosis (CME), as significantly lower fluorescent intensity was observed when metabolic inhibitor sucrose hypertonic treatment was employed. Figure 3 (B\& D) further, corroborate 
the same, as the fluorescence intensity in the cells treated with sucrose as inhibitor is significantly less. Mechanistically, CME involves engulfment of receptors associated with their ligands to a coated pit. The coated pit forms due to polymerization of a cytosolic protein called clathrin-1, which also requires assembly proteins like AP180 and AP-2 (HarushFrenkel et al., 2007). Poly(lactic-co-glycolic acid) (Panyam and Labhasetwar, 2003), silicabased (Nan et al., 2008) and cationic chitosan nanoparticles (Huang et al., 2002) have been shown to utilize CME for cellular internalization. The authors here for the very first time report the mechanism by which the SNELS are being uptaken by the cancerous cells.

\subsection{Apoptosis Assay}

Detection of phosphatidylserine by fluorescence-assisted detection with PI is well established technique to measure apoptosis. Intact cells are stained negative for both Annexin V and PI (Rieger et al., 2011). Early apoptotic cells and late apoptosis can be distinguished based on "Annexin-positive" and "Annexin with PI positivity" respectively, while necrosis or cell death during processing can be identified using "PI only" signal. Flow cytometric study with Annexin V assay showed that $99.69 \%$ and $99.83 \%$ of control MCF-7 and MDA-MB231 culture cells $(\mathrm{p}>0.05)$ were viable (Figure 4 A\&E). The percentages of apoptotic cells (including early and late) in MCF-7 cells treated with Blank SNELS, DTH and DTH-SNELS were $25.58 \% \pm 2.21 \%, 47.88 \% \pm 5.32 \%$, and $79.28 \pm 6.89 \%$, respectively (Figure 4 B-D), while the percentages of apoptotic cells in MDA-MB-231 cells treated with blank SNELS, DTH and DTH-SNELS were $21.69 \% \pm 1.78 \%, 41.34 \% \pm 4.72 \%$, and $81.81 \% \pm 7.38 \%$, respectively (Figure $4 \mathrm{~F}-\mathrm{H})$.

These results indicate that the percentage of apoptotic cells induced by DTH-SNELS was much higher than free drug in both MCF-7 cells $(1.65$ fold $)$ and MDA-MB-231 cells $(\approx 2$ folds). This significant increased percentage of apoptotic cells caused by DTH-SNELS in 
comparison with free drug may be attributed to the improved cellular uptake of DTH-SNELS indicating the superiority of DTH-SNELS and its potential use in aggressive TNBC.

\subsection{Cell Cycle Arrest}

It has been reported that DTH acts at molecular level by debilating mitosis, impairs proliferation of tumor cells and inducing cell cycle arrest (Harush-Frenkel et al., 2007; Hernandez-Vargas et al., 2007). Flow cytometry studies were performed to determine the differences in cell cycle distribution among the treatments [Figure 5(i)]. Table 1 depicts the results after treating MCF-7 and MDA-MB-231 cells for $24 \mathrm{~h}$ with free DTH or DTH-SNELS at IC50 values. DTH-SNELS treatment induced accumulation in G2/M with a significant decrease in G0/G1 phase versus control cells. After exposure to DTH SNELS, there was 1.86 folds decrease of MDA-MB-231 (from $72.5 \%$ to $38.9 \%$ ), and 1.48 folds decrease of MCF-7 cells (from $60.3 \%$ to $40.6 \%$ ) in the G1 phase. The accumulation in G2/M phase after DTHSNELS treatment was 2.21 and 2.17 times greater than free DTH in MCF-7 and MDA-MB231 cells respectively. The rapid decrease in cell cycle progression, testified by the increased percentage of cells G2/M phase evidence for potential clinical applications of DTH-SNELS in both TNBC and non TNBC (Liu et al., 2011; Yuan et al., 2014b). Figure 5(i) portrays the ratio of early and late apoptotic stages and have been summarized in Table 1.

\subsection{P-gp Efflux Assay}

The P-gp efflux assay revealed that both the dyes (i.e., Rh-123 and $\mathrm{DiOC}_{2}$ ), were efflux out at $37^{\circ} \mathrm{C}$, as evident from lack of intracellular accumulation of the fluorescent dye in MCF-7 and MDA-MB-231 cells (Figure $4 \mathrm{J \& K}$ ). On the other hand, incubation with P-gp efflux inhibitor, i.e., vinblastine showed that dyes after coupling with the former, block both MDR1 and BCRP transporters at $37^{\circ} \mathrm{C}$, eventually leading to higher fluorescence intensity without any efflux. DTH-SNELS interfered with the microenvironment of P-gp and weakened the P-gp mediated efflux, as apparent from higher accumulation of Rh-123 and 
DiOC $_{2}$ dyes in both the cell lines, suggesting MDR1 and BCRP transporters were not functional. Accordingly, the excipients of DTH- SNELS, i.e., Tween 80 play a major role in inhibiting the P-gp efflux and significantly reduced transporter efficiencies for the P-gp substrate, i.e., Rh-123 and $\mathrm{DiOC}_{2}$ dyes (Khurana et al 2017 (b).

\subsection{Macrophage uptake}

Nanoparticles are very efficiently scavenged from circulating blood and tissues by macrophages resident in tissue and filtration organs (MPS system), severely limiting particle targeting Gustafson et al., 2015). Though qualitative and quantitative estimation confirmed higher uptake of DTH-SNELS by MCF-7 (fluorescence intensity of 98) and MDA-MB-231 (fluorescence intensity of 71) cells [Figure $4(\mathrm{M} \& \mathrm{~N})]$. Nevertheless, DTH-SNELS were uptaken to much lower extent (fluorescence intensity of 19) by the macrophages when incubated for 4h with RAW 264.7 [Figure 4(L)]. This would limit rapid blood clearance of DTH-SNELS and would lead to accumulation at target delivery sites (Beddoes et al., 2015)

\subsection{In vivo toxicity studies}

Figure 5(ii) shows histopathological findings on comparing with (A) normal rat after administering, (B) plain DTH, (C) blank SNELS formulation, (D) DTH-SNELS. (1) Kidney (A) glomeruli, tubules and blood vessels are within normal limits; (B) glomeruli, tubules and blood vessels are within normal limits while the interstitium shows focal moderate to dense lymphocytic inflammatory infiltrate; (C) glomeruli, tubules and blood vessels are within normal limits; (D) renal medulla shows multiple foci of microscopic hemorrhage and rest of renal parenchyma is within normal limits. (2) Heart (A) endocardium, epicardium and myocardium do not show significant changes; (B) endocardium and epicardium are normal whereas the myocardium shows degenerative changes in the myocytes, extensive interstitial oedema and inflammatory cells (which are chiefly macrophages); (C) endocardium, 
epicardium and myocardium do not show any significant changes; (D) subendocardial inflammation which extends into the underlying myocardium and the inflammatory cells are chiefly lymphocytes. (3) Small intestine (A-D) Ileum shows normal villi and brush borders. No other significant changes are observed. (4) Large intestine (A-D) Mucosa, submucosa, muscularis serosae are within normal limits. (5) Spleen (A-D) Spleenic red and white pulp doesn't show are within normal limits. (6) Pancreas (A,B,C\&D) pancreatic acini and islets do not show any significant changes. (7) Liver (B) Liver shows occasional focus of necrosis in mid zone; (A,C\&D) the portal tracts, central vein sinusoids do not show any significant changes. (8) Stomach (A-D) Mucosa, submucosa, muscularis and serosa do not show any significant changes.

The whole blood count revealed that the plain DTH solution was significantly $(\mathrm{p}<0.001)$ affecting the white blood cells $(\mathrm{WBC})$ count, red blood cells $(\mathrm{RBC})$ count, haemoglobin (HGB), haematocrit (HCT) and platelet (PLT) count, in consonance the wellknown fact that the chemotherapy could decrease the whole blood count. Further, with DTHSNELS, there was a significant reduction in the whole blood count $(\mathrm{p}<0.05)$. No significant effect on blood count, however, was observed with blank SNELS on comparison with control ( $>0.05$ ). Table 2 depicts the precise values of the whole blood count parameters for all the treatments.

Further, the slides of blood samples were prepared and observed under upright light microscope. Results showed that there were agglomerations with plain DTH [Figure 5 (iii)B] while the blank and DTH-SNELS didn't show any morphological changes in the shape of $\mathrm{RBC}$ and were more or less similar to control [Figure 5 (iii) C \& D].

Figure 5 (iv) shows the amount of DTH distributed in various organs. It was observed that the DTH concentration was significantly higher than DTH-SNELS in kidney, heart and liver $(p<0.05)$. Also, insignificant DTH concentration $(p>0.05)$ was recorded in other vital 
organs. Further, it was examined that the results of histopathology are inconsonance with biodistribution.

\subsection{In Vivo Antitumor Efficacy}

Figure 6 B shows slight tumor regression after repetitive oral administration of DTH vis-a-vis control tumor (Figure 6A) while major tumor size inhibition after treating with DTH SNELS (Figure 6 C) for 30 days. The volume of the control tumor after 30 days was recorded as $14.14 \mathrm{~cm}^{3}$ (Figure $6(\mathrm{~A})$, while of DTH treated animals showed some regression with tumor volume of $10.31 \mathrm{~cm}^{3}(\mathrm{p}<0.05)$ (Figure $6(\mathrm{~B})$. While DTH-SNELS treated animals showed 8.96 times lower tumor volume $\left(1.1508 \mathrm{~cm}^{3} ; \mathrm{p}<0.001\right)$. These results were confirmed with histopathology of the excised tumor (Figure 6 (D,E,F) tissue (Garg et al., 2016). The residual tumor burden in percentage was $27.08 \%$ and $91.86 \%$ in case of DTH-SNELS and DTH, respectively, whereas the untreated animal group showed an increase in tumor volume up to $141.40 \%$ (Figure 6G). Figure $6 \mathrm{H}$ represents the Kaplan-Meier survival plot after 60 days of repetitive treatment with DTH and DTH formulations. No mortality was recorded in the animal group treated with DTH-SNELS, whereas about $50 \%$ deaths occurred in the animal groups treated with DTH.

\section{Discussion}

DTH has generated keen interest among several scientists across the world owing to its clinical utility in many of the solid tumors, like breast, stomach, lung and prostate cancers (Hekmat et al., 2016). Being active cytotoxic agent, it is known to promote the polymerization of tubulin and stabilization of microtubules by preventing their disassembly. However, its clinical application is hampered primarily owing to several of its severe side effects, such as myelosuppression, neutropenia, anemia, hypersensitivity reaction and doserelated toxicity (Yuan et al., 2014a). Apart from the clinical issues, other ostensible physicochemical challenges encountered with DTH include, poor aqueous solubility, low 
intestinal permeability with poor and inconsistent bioavailability (Feng and Mumper, 2012; Valicherla et al., 2016). Therefore, in order to surmount the challenges and minimise its side effects, while keeping its antitumor activity intact, there is an ardent need to develop its newer nano formulations with improved safety and efficacy. Several nanotechnology-based formulations have already proved to exhibit promising results, like polymeric nanoparticles (Hwang et al., 2008), solid lipid nanoparticles (Xu et al., 2009), emulsions (Yanasarn et al., 2009), liposomes (Liang et al., 2007), self nanoemulsifying drug delivery systems (Seo et al., 2013) and micelles (Elsabahy et al., 2007).

Compared with other nanoformulations, the SNELS enhance the bioavailability of BCS Class II drugs like DTH, exhibiting poor solubility and lower permeability. It has other added advantages, including easier preparation, improved stability, enhanced scalability, better safety and market potential. Also, Omega-3 PUFA such as linolenic acid are naturally occurring energy resources utilized as cellular membrane components and play an important role in cell growth (Ojima et al., 2012). PUFAs have been uptaken more rapidly by tumor tissue than normal cells. Being lipophilic in nature, it has shown that PUFAs get readily incorporated into the lipid bilayer of tumor cells, and thereby disrupting the morphology of the cell and presumably influences the susceptibility of the tumor cells to anticancer agents. Therefore, PUFAs can be used as an applicable carrier to increase the therapeutic efficacy of anticancer drugs (Wang et al., 2012).

The current research work testifies the immense drug delivery potential of PUFA based DTH-SNELS through improved in vitro and in vivo efficacy and thereby, enhanced its anti-tumor activity. The systematically optimized SNELS comprised of isotropic mixture of omega-6 Maisine-35-1, Tween 80 (a hydrophilic surfactant) and Transcutol HP (a cosurfactant). Characterization of the DTH-SNELS proved spontaneous formation of the nanoemulsions, with low emulsification time $(<3 \mathrm{~min})$ and smaller globule size $(\sim 100 \mathrm{~nm})$ 
(Khurana et al., 2017(a). The extent and rate of absorbed drug in the gastrointestinal tract are related to the carrier size and surface properties (Bandyopadhyay et al., 2015; Tripathi et al., 2016).

Many previously reported studies have shown that DTH suppresses growth of tumor cells (Yuan et al., 2014a; Vardhan et al., 2016; Zhu et al., 2016). Further, DTH-SNELS was evaluated for cell viability, cellular uptake quantitation and mechanism, apoptosis and cell cycle assay in MCF-7 and MDA-MB-231 cells, and in vivo safety and efficacy studies in SD rats. Cell lines of luminal and basal origin were selected to study any differential behavior in DTH sensitivity, as basal phenotype is known to show chemo-resistance (Choi et al., 2014).

Cell viability assay indicates cell-line dependent behavior of DTH-SNELS. DTH is known to have lower activity in MDA-MB231 as compared to MCF-7 cells (Alami et al. (2007) Of significance is that DTH-SNELS showed 3.3 times lower $\mathrm{IC}_{50}$ in MDA-MB-231 TNBC cells as compared with free DTH showing its potential in treatment of TNBC (Table S1). Presently TNBC have poor prognosis with a recent study after a 38 month follow up showed only $72 \%$ of TNBC patients were still alive as compared with $92 \%$ of non-TNBC patients (Joyce et al., 2017). Obviously, as expected DTH-SNELS proved to be highly efficacious in MCF-7 cells with 9 times lower IC50 as compared to free DTH authenticating its promise in non TNBC also. Cell uptake studies corroborated with the findings obtained in cell viability studies, as overall drug accumulation was higher in MCF-7 cells vis-à-vis MDA-MB-231 cells (Wawruszak et al., 2015). Difference in activity profile between both cell lines could be attributed to variation in intracellular DTH accumulation. Already, Britton et al. (2012) have reported the drug resistance behavior of MDA-MB-231 cells and expression of high levels of efflux protein, (ABCG-2) (Britton et al., 2012).

Further, MDA-MB-231 cells are known to attenuate intracellular gradient of chemotherapeutics. On the similar lines, the authors have also observed higher and faster Rh- 
123-DTH-SNELS loading inside the MCF-7 cells as compared to MDA-MB-231. Moreover, no additional increase in fluorescence intensity was observed signifying that the cells were getting saturated after a particular time-point, i.e., 4h (Jiang et al., 2013).

For studying the mechanism of drug uptake, various kinds of endocytotic inhibitors were employed, and it was observed that the micelles were taken-up by Clathrin-mediated pathway, as the fluorescent intensity was significantly lower in sucrose pre-treated cells, for both MCF-7 and MDA-MB-231 cells. Also, no fluorescence was observed at $4^{\circ} \mathrm{C}$, suggesting that the cellular uptake of DTH-SNELS was by active transport only (Kam et al., 2006; Thurn et al., 2010; Vilella et al., 2015).

While DTH-SNELS showed significant level of cell death, it is imperative to check whether or not it is induced as programmed cell death, i.e. apoptosis. Annexin-V apoptosis assay was conducted to analyse the apoptosis in MCF-7 and MDA-MB-231 cells, which revealed that DTH-SNELS are quite effective in killing both the cell types (Attia et al., 2016). Again, the observation was that DTH-SNELS were more senstive to MCF-7 than to MDA-MB-231 cells. Further, cell cycle analysis results revealed that both the cell lines were arrested at G2/M phase, thus vividly supporting the results of cytotoxicity (Nehme et al., 2001; Morse et al., 2005). Further, the excipients of SNELS inhibit the P-gp efflux enabling the DTH-loaded formulation to enter the cancerous cells and are measured as a function of increased fluorescence intensity. The usage of surfactant in these nano micellar systems bring upon membrane perturbation and P-gp inhibition with enhanced drug permeability (Wu et al., 2006). Tween 80 having both lipophilic and hydrophilic attributes, partitions between lipid and protein domains in the intestinal membrane disrupting its integrity and plausibly increasing the permeability of DTH (Khurana et al., 2017 (a).

Interestingly DTH-SNELS showed much lower uptake by Raw 264.7 macrophage cells. This could be due the small size of SNELS $(<100 \mathrm{~nm})$ coupled with hydrophilic barrier due 
to prescence of Tween 80 that plausibly sterically prevents protein adsorption and subsequently adhesion of nanoparticles to macrophage cells and thus decrease the uptake by macrophage cells. (Perry et al., 2012; Moayedian et al., 2015). This would also prolong the blood circulation of the nanoparticles with significant reduction in opsonization and thus improved delivery to the target tissues.

Besides effective cell killing during cell viability and apoptosis assay, histopathological changes were observed only with the plain DTH, which showed morphological alterations in kidney's glomeruli, tubules and blood vessels, and were more severe with plain DTH. Heart histopathology also showed changes in endocardium, epicardium and myocardium, while cerebral cortex showed occasional microglial nodules, which again was found to be bit severe with plain DTH. Further, WBC, RBC, HGB and HCT levels were depleted with plain DTH, which indicated toxicity. However, no toxicity was observed with blank SNELS as well as DTH-SNELS. This vouches distinct utility of SNELS in improving the safety profile of DTH. In vivo tumor efficacy revealed significant reduction in the tumor size $(\mathrm{p}<0.05)$, when treated with optimized SNELS, thus ratifying the effective anti-tumor activity and potential patient benefit in this deadly disease.

\section{Conclusions}

In this study, systematically developed PUFA incorporated self-nanoemulsifying lipidic micellar systems have proven to be significantly efficacious $(p<0.05)$ in terms of inhibiting the growth of TNBC and non-TNBC cell lines in vitro as well as tumor growth in DMBA induced tumor model in vivo. Furthermore, this is the first report on the lipidic nano micelles in terms of unearthing their clathrin-mediated endocytic uptake in the cancerous cells which is hitherto uncovered in the literature. Overall, these results suggest that DTH-SNELS has great potential in breast cancer therapeutics. Its usefulness in triple negative breast cancer is 
of significance as current treatments have poor prognosis of the disease and there is dire need of new treatments .

\section{Conflict of Interest:}

The authors declare that there are no conflicts of interest.

\section{Acknowledgements:}

RK Khurana acknowledges the grants received from the University Grant Commission (UGC), New Delhi, India, to carry out the present research work, while working as a UGC Research Fellow under RFMS scheme, F.No. 5-(94)/2007/(BSR). The use of biomedical facilities of University of Central Lancashire for the cell culture work is deeply acknowledged. The authors have no other relevant affiliations or financial involvement with any organization or entity with a financial interest in or financial conflict with the subject matter or materials discussed in the manuscript apart from those disclosed.

No writing assistance was utilized in the production of this manuscript.

\section{References:}

Alami, N., Paterson, J., Belanger, S., Juste, S., Grieshaber, C.K., Leyland-Jones, B., 2007. Comparative analysis of xanafide cytotoxicity in breast cancer cell lines. Br J Cancer. 97, 58-64.

Athawale, R.B., Jain, D.S., Singh, K.K. Gude, R.P. 2014, Etoposide loaded solid lipid nanoparticles for curtailing B16F10 melanoma colonization in lung. Biomedicine \& Pharmacotherapy, 68, (2), 231-240. Attia, R.T., Tolba, M.F., Trivedi, R., Tadros, M.G., Arafa, H.M.M., Abdel-Naim, A.B., 2016. The chemomodulatory effects of glufosfamide on docetaxel cytotoxicity in prostate cancer cells. PeerJ 4 , e2168.

Bandyopadhyay, S., Beg, S., Katare, O.P., Sharma, G., Singh, B., 2015. QbD-oriented development of self-nanoemulsifying drug delivery systems (SNEDDS) of valsartan with improved biopharmaceutical performance. Curr Drug Deliv 12, 544-563.

Bao, L., Hazari, S., Mehra, S., Kaushal, D., Moroz, K., Dash, S., 2012. Increased expression of PGlycoprotein and doxorubicin chemoresistance of metastatic breast cancer is regulated by miR-298. Am J Pathol. 180, 2490-2503.

BAUER, K. R., BROWN, M., CRESS, R. D., PARISE, C. A. \& CAGGIANO, V. 2007. Descriptive analysis of estrogen receptor (ER)-negative, progesterone receptor (PR)-negative, and HER2-negative invasive breast cancer, the so-called triple-negative phenotype. Cancer, 109, 1721-1728

Beg, S., Jena, S.S., Patra, C.N., Rizwan, M., Swain, S., Sruti, J., Rao, M.E., Singh, B., 2013. Development of solid self-nanoemulsifying granules (SSNEGs) of ondansetron hydrochloride with enhanced bioavailability potential. Colloids Surf B Biointerfaces 101, 414-423.

Britton, K.M., Eyre, R., Harvey, I.J., Stemke-Hale, K., Browell, D., Lennard, T.W., Meeson, A.P., 2012. Breast cancer, side population cells and ABCG2 expression. Cancer Lett 323, 97-105. 
Bougnoux P, Hajjaji N, Maheo K, et al. 2010. Fatty acids and breast cancer: sensitization to treatments and prevention of metastatic regrowth.Prog Lipid Res 49,76-86.

Cecchini, M.J., Amiri, M., Dick, F.A., 2012. Analysis of cell cycle position in mammalian cells. J Vis Exp, 3491.

Beddoes, C. M., Case, C. P., .Briscoe W. H., 2015. Understanding nanoparticle cellular entry: A physicochemical perspective. Advances in Colloid and Interface Science, 218, 48-68

Choi, W., Porten, S., Kim, S., Willis, D., Plimack, E.R., Hoffman-Censits, J., Roth, B., Cheng, T., Tran, M., Lee, I.L., Melquist, J., Bondaruk, J., Majewski, T., Zhang, S., Pretzsch, S., Baggerly, K., SiefkerRadtke, A., Czerniak, B., Dinney, C.P.N., McConkey, D.J., 2014. Identification of distinct basal and luminal subtypes of muscle-invasive bladder cancer with different sensitivities to frontline chemotherapy. Cancer Cell 25, 152-165.

Elsabahy, M., Perron, M.E., Bertrand, N., Yu, G.E., Leroux, J.C., 2007. Solubilization of docetaxel in poly(ethylene oxide)-block-poly(butylene/styrene oxide) micelles. Biomacromolecules. 8, 2250-2257.

Feng, L., Mumper, R.J., 2012. A critical review of lipid-based nanoparticles for taxane delivery. Cancer Lett 334, 157-175.

Garanti, T., Stasik, A., Burrow, A.J., Alhnan, M.A., Wan, K.W., 2016. Anti-glioma activity and the mechanism of cellular uptake of asiatic acid-loaded solid lipid nanoparticles. Int J Pharm 500, 305315.

Garg, N.K., Singh, B., Kushwah, V., Tyagi, R.K., Sharma, R., Jain, S., Katare, O.P., 2016. The ligand (s) anchored lipobrid nanoconstruct mediated delivery of methotrexate: an effective approach in breast cancer therapeutics. Nanomedicine 12, 2043-2060.

Gustafson, H.H., Holt-Casper, D., Grainger,D.W., Ghandehari, H., 2015. Nanoparticle uptake: The phagocyte problemNano Today10, 487-510.

Harush-Frenkel, O., Debotton, N., Benita, S., Altschuler, Y., 2007. Targeting of nanoparticles to the clathrin-mediated endocytic pathway. Biochem Biophys Res Commun. 353, 26-32.

He, S., Liu, F., Xie, Z., Zu, X., Xu, W., Jiang, Y., 2010. P-Glycoprotein/MDR1 regulates Pokemon gene transcription through p53 expression in human breast cancer cells. Int J Mol Sci 11, 3309-3051.

Hekmat, A., Attar, H., Seyf Kordi, A.A., Iman, M., Jaafari, M.R., 2016. New oral formulation and in vitro evaluation of docetaxel-loaded nanomicelles. Molecules 21(9). E1265.

Hernandez-Vargas, H., Palacios, J., Moreno-Bueno, G., 2007. Molecular profiling of docetaxel cytotoxicity in breast cancer cells: uncoupling of aberrant mitosis and apoptosis. Oncogene. 26, 2902-2913.

Huang, M., Ma, Z., Khor, E., Lim, L.Y., 2002. Uptake of FITC-chitosan nanoparticles by A549 cells. Pharm Res. 19, 1488-1494.

Hwang, H.Y., Kim, I.S., Kwon, I.C., Kim, Y.H., 2008. Tumor targetability and antitumor effect of docetaxel-loaded hydrophobically modified glycol chitosan nanoparticles. J Control Release. 128, 2331.

Jain AK, T.K., Jain S., 2014. Solidified self-nanoemulsifying formulation for oral delivery of combinatorial therapeutic regimen: part II in vivo pharmacokinetics, antitumor efficacy and hepatotoxicity. Pharm Res 31, 946-958.

Jia, T., Zhang, L., Duan, Y., Zhang, M., Wang, G., Zhang, J., Zhao, Z., 2014. The differential susceptibilities of MCF-7 and MDA-MB-231 cells to the cytotoxic effects of curcumin are associated with the PI3K/Akt-SKP2-Cip/Kips pathway. Cancer Cell Int 14:126., doi: 10.1186/s12935-1201410126-12934.

Jiang, L., Li, X., Liu, L., Zhang, Q., 2013. Cellular uptake mechanism and intracellular fate of hydrophobically modified pullulan nanoparticles. Int J Nanomedicine 8, 1825-1834.

Joyce, D.P., Murphy, D., Lowery, A.J., Curran, C., Barry, K., Malone, C., McLaughlin, R., Kerin, M.J.

2017. Prospective comparison of outcome after treatment for triple-negative and non-triple negative breast cancer, The Surgeon, Journal of the Royal Colleges of Surgeons of Edinburgh and Ireland. 15(5), 272-277 
Kalimutho, M., Parsons, K., Mittal, D., López, J.A., Srihari, S., Khanna, K.K., 2015.Targeted therapies for triple-negative breast cancer: combating a stubborn disease.Trends in Pharmacological Sciences, $36,12822-846$

Kam, N.W., Liu, Z., Dai, H., 2006. Carbon nanotubes as intracellular transporters for proteins and DNA: an investigation of the uptake mechanism and pathway. Angew Chem Int Ed Engl. 45, 577-581.

Khurana, R.K., Beg, S., Burrow, A.J., Vashishta, R.K., Katare, O.P., Kaur, S., Kesharwani, P., Singh, K.K., Singh, B., 2017 (a). Enhancing biopharmaceutical performance of an anticancer drug by long chain PUFA based self-nanoemulsifying lipidic nanomicellar systems. Eur J Pharm Biopharm 121, 42-60.

Khurana, R.K., Mahajan, M., Teenu, Kapoor, S., Jain, S., Singh, B., 2016. The sojourn from parenteral to oral taxanes using nanocarrier systems: A patent review. Recent Drug Deliv Formul 10, 44-58.

Khurana RK, Bansal AK, Beg S, Burrow AJ, Katare OP, Singh KK, et al. 2017 (b). Enhancing biopharmaceutical attributes of phospholipid complex-loaded nanostructured lipidic carriers of mangiferin: systematic development, characterization and evaluation. Int J Pharm 518(1-2), 289306.

Khurana, R.K., Gaspar, B.L., Welsby, G. et al. Drug Deliv. and Transl. Res. 2018. https://doi.org/10.1007/s13346-018-0498-4

Liang, G., Jia-Bi, Z., Fei, X., Bin, N., 2007. Preparation, characterization and pharmacokinetics of Npalmitoyl chitosan anchored docetaxel liposomes. J Pharm Pharmacol. 59, 661-667.

Liang, X.J., Chen, C., Zhao, Y., Wang, P.C., 2010. Circumventing tumor resistance to chemotherapy by nanotechnology. Methods Mol Biol 596, 467-488.

Lin Mei, Y.Z., Yi Zheng, Ge Tian, Cunxian Song, Dongye Yang, Hongli Chen, Hongfan Sun, Yan Tian, Kexin Liu, Zhen Li, Laiqiang Huang, 2009. A Novel Docetaxel-Loaded Poly (Î $\mu$-Caprolactone)/Pluronic F68 Nanoparticle Overcoming Multidrug Resistance for Breast Cancer Treatment. Nanoscale Res Lett 4, 1530-1539. doi:1510.1007/s11671-11009-19431-11676.

Liu, D., Liu, Z., Wang, L., Zhang, C., Zhang, N., 2011. Nanostructured lipid carriers as novel carrier for parenteral delivery of docetaxel. Colloids Surf B Biointerfaces. 85, 262-269.

Martins S, C.-L.S., Carneiro T, Cordeiro-da-Silva A, Souto EB, Ferreira DC., 2012. Solid lipid nanoparticles as intracellular drug transporters: an investigation of the uptake mechanism and pathway. Int J Pharm 430, 216-227.

Montero, A., Fossella, F., Hortobagyi, G., Valero, V., 2005. Docetaxel for treatment of solid tumours: A systematic review of clinical data. Lancet Oncol. 6, 229-239.

Morse, D.L., Gray, H., Payne, C.M., Gillies, R.J., 2005. Docetaxel induces cell death through mitotic catastrophe in human breast cancer cells. Mol Cancer Therapeutics 10.

Nan, A., Bai, X., Son, S.J., Lee, S.B., Ghandehari, H., 2008. Cellular uptake and cytotoxicity of silica nanotubes. Nano Lett. 8, 2150-2154.

Nehme, A., Varadarajan, P., Sellakumar, G., Gerhold, M., Niedner, H., Zhang, Q., Lin, X., Christen, R.D., 2001. Modulation of docetaxel-induced apoptosis and cell cycle arrest by all- trans retinoic acid in prostate cancer cells. Br J Cancer. 84, 1571-1576.

Ojima, I., Zuniga, E.S., Berger, W.T., Seitz, J.D., 2012. Tumor-targeting drug delivery of newgeneration taxoids. Future Med Chem. 4, 33-50.

Ovcaricek, T., Frkovic, S.G., Matos, E., Mozina, B., Borstnar, S., 2011. Triple negative breast cancer prognostic factors and survival. Radiol Oncol. 45, 46-52.

Panyam, J., Labhasetwar, V., 2003. Dynamics of endocytosis and exocytosis of poly(D,L-lactide-coglycolide) nanoparticles in vascular smooth muscle cells. Pharm Res. 20, 212-220.

Pozarowski P, D.Z., 2004. Analysis of cell cycle by flow cytometry. Methods Mol Biol 281, 301-311.

Reddel, R.R., Murphy, L.C., Hall, R.E., Sutherland, R.L., 1985. Differential sensitivity of human breast cancer cell lines to the growth-inhibitory effects of tamoxifen. Cancer Res. 45, 1525-1531. 
Rieger, A.M., Nelson, K.L., Konowalchuk, J.D., Barreda, D.R., 2011. Modified annexin V/propidium iodide apoptosis assay for accurate assessment of cell death. J Vis Exp 50, pii:2597.

Sandhu, P.S., Kumar, R., Beg, S., Jain, S., Kushwah, V., Katare, O.P., Singh, B., 2017. Natural lipids enriched self-nano-emulsifying systems for effective co-delivery of tamoxifen and naringenin: Systematic approach for improved breast cancer therapeutics. Nanomedicine. 13, 1703-1713.

Seo, Y.G., Kim, D.H., Ramasamy, T., Kim, J.H., Marasini, N., Oh, Y.K., Kim, D.W., Kim, J.K., Yong, C.S., Kim, J.O., Choi, H.G., 2013. Development of docetaxel-loaded solid self-nanoemulsifying drug delivery system (SNEDDS) for enhanced chemotherapeutic effect. Int J Pharm 452, 412-420.

Stanton, R.A., Gernert, K.M., Nettles, J.H., Aneja, R., 2011. Drugs That Target Dynamic Microtubules: A New Molecular Perspective. Med Res Rev. 31, 443-481.

Thurn, K.T., Arora, H., Paunesku, T., Wu, A., Brown, E.M., Doty, C., Kremer, J., Woloschak, G., 2010. Endocytosis of titanium dioxide nanoparticles in prostate cancer PC-3M cells. Nanomedicine 7, 123130.

Tripathi, C.B., Beg, S., Kaur, R., Shukla, G., Bandopadhyay, S., Singh, B., 2016. Systematic development of optimized SNEDDS of artemether with improved biopharmaceutical and antimalarial potential. Drug Deliv 23, 3209-3223.

Valicherla, G.R., Dave, K.M., Syed, A.A., Riyazuddin, M., Gupta, A.P., Singh, A., Wahajuddin, Mitra, K., Datta, D., Gayen, J.R., 2016. Formulation optimization of docetaxel loaded self-emulsifying drug delivery system to enhance bioavailability and anti-tumor activity. Sci Rep 6, 26895.

Vardhan, H., Mittal, P., Adena, S.K., Mishra, B., 2016. Long-circulating polyhydroxybutyrate-cohydroxyvalerate nanoparticles for tumor targeted docetaxel delivery: Formulation, optimization and in vitro characterization. Eur J Pharm Sci 99, 85-94.

Vilella, A., Ruozi, B., Belletti, D., Pederzoli, F., Galliani, M., Semeghini, V., Forni, F., Zoli, M., Vandelli, M.A., Tosi, G., 2015. Endocytosis of nanomedicines: The case of glycopeptide engineered PLGA nanoparticles. Pharmaceutics. 7, 74-89.

Wang, J., Luo, T., Li, S., Zhao, J., 2012. The powerful applications of polyunsaturated fatty acids in improving the therapeutic efficacy of anticancer drugs. Expert Opin Drug Deliv. 9, 1-7.

Wang, Z., Zhang, X., 2017. Chemopreventive activity of honokiol against 7, 12 dimethylbenz[a]anthracene-induced mammary cancer in female sprague dawley rats. Front Pharmacol. 8:320., 10.3389/fphar.2017.00320. eCollection 02017.

Wawruszak, A., Luszczki, J.J., Grabarska, A., Gumbarewicz, E., Dmoszynska-Graniczka, M., Polberg, K., Stepulak, A., 2015. Assessment of interactions between cisplatin and two histone deacetylase inhibitors in MCF7, T47D and MDA-MB-231 human breast cancer cell lines - An isobolographic analysis. PLoS One 10, e0143013.

Wiggins, A.K., Kharotia, S., Mason, J.K., Thompson, L.U., 2015. Alpha-linolenic acid reduces growth of both triple negative and luminal breast cancer cells in high and low estrogen environments. Nutr Cancer 67, 1001-1009.

Wu, W., Wang, Y., Que, L., 2006. Enhanced bioavailability of silymarin by self-microemulsifying drug delivery system. Eur J Pharm Biopharm. 63, 288-294.

Xu, Z., Chen, L., Gu, W., Gao, Y., Lin, L., Zhang, Z., Xi, Y., Li, Y., 2009. The performance of docetaxelloaded solid lipid nanoparticles targeted to hepatocellular carcinoma. Biomaterials. 30, 226-232.

Yanasarn, N., Sloat, B.R., Cui, Z., 2009. Nanoparticles engineered from lecithin-in-water emulsions as a potential delivery system for docetaxel. Int J Pharm. 379, 174-180.

Yuan, Q., Han, J., Cong, W., Ge, Y., Ma, D., Dai, Z., Li, Y., Bi, X., 2014a. Docetaxel-loaded solid lipid nanoparticles suppress breast cancer cells growth with reduced myelosuppression toxicity. Int J Nanomedicine. 9, 4829-4846.

Yuan, Q., Han, J., Cong, W., Ge, Y., Ma, D., Dai, Z., Li, Y., Bi, X., 2014b. Docetaxel-loaded solid lipid nanoparticles suppress breast cancer cells growth with reduced myelosuppression toxicity. Int J Nanomedicine. 9:4829-46., 10.2147/IJN.S70919. eCollection 72014. 
Zhu, W., Li, D., Li, X., Ren, J., Chen, W., Gu, H., Shu, Y., Wang, D., 2016. Association between adjuvant docetaxel-based chemotherapy and breast cancer-related lymphedema. Anticancer Drugs, doi: 10.1097/CAD.0000000000000468.

\section{FIGURES}
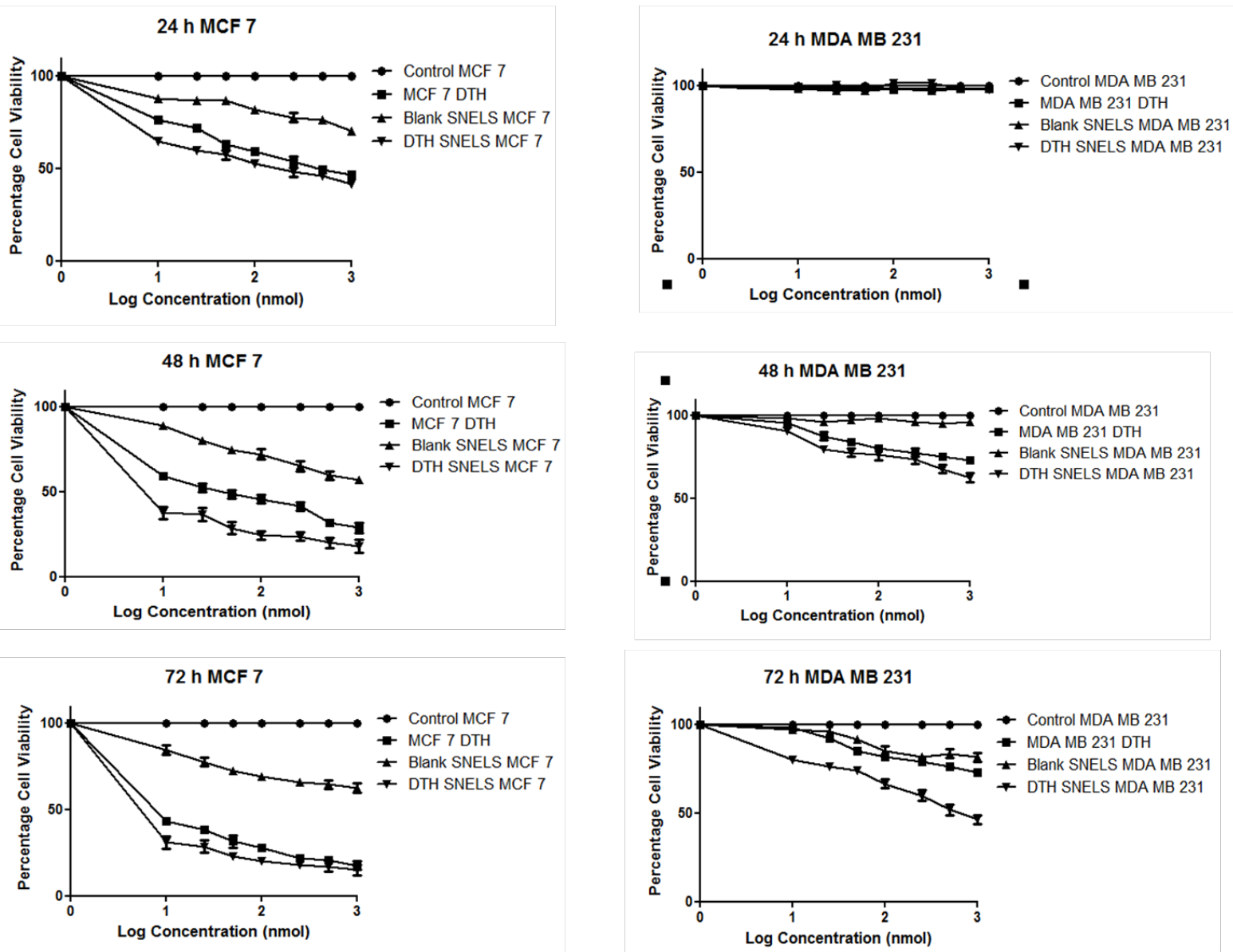

Figure 1: Time and dose dependent inhibition of cell growth by different concentrations of DTH, blank and DTH SNELS at $24 \mathrm{~h}(\mathrm{~A}, \mathrm{D}), 48 \mathrm{~h}$ (B, E), $72 \mathrm{~h}$ $(C, F)$ in MCF-7 and MDA-MB-231 cells. Data shown here is Mean \pm SD from 3 independent experiments. 

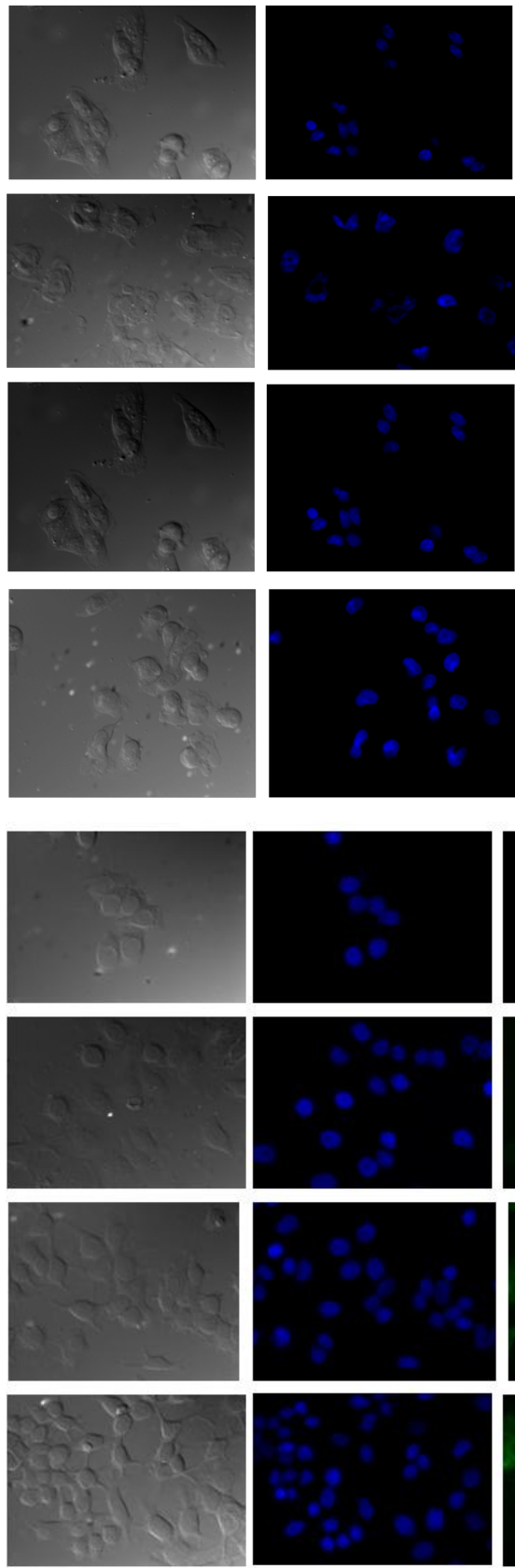

(A)
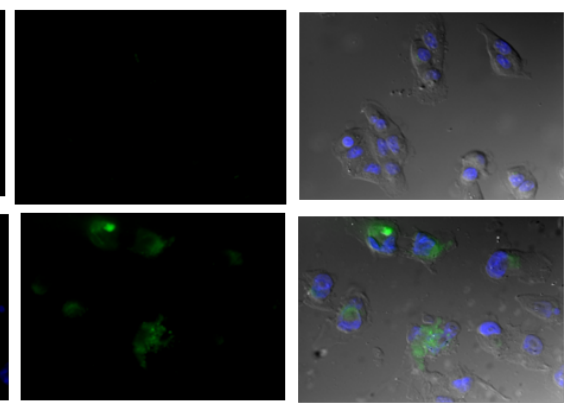

Control
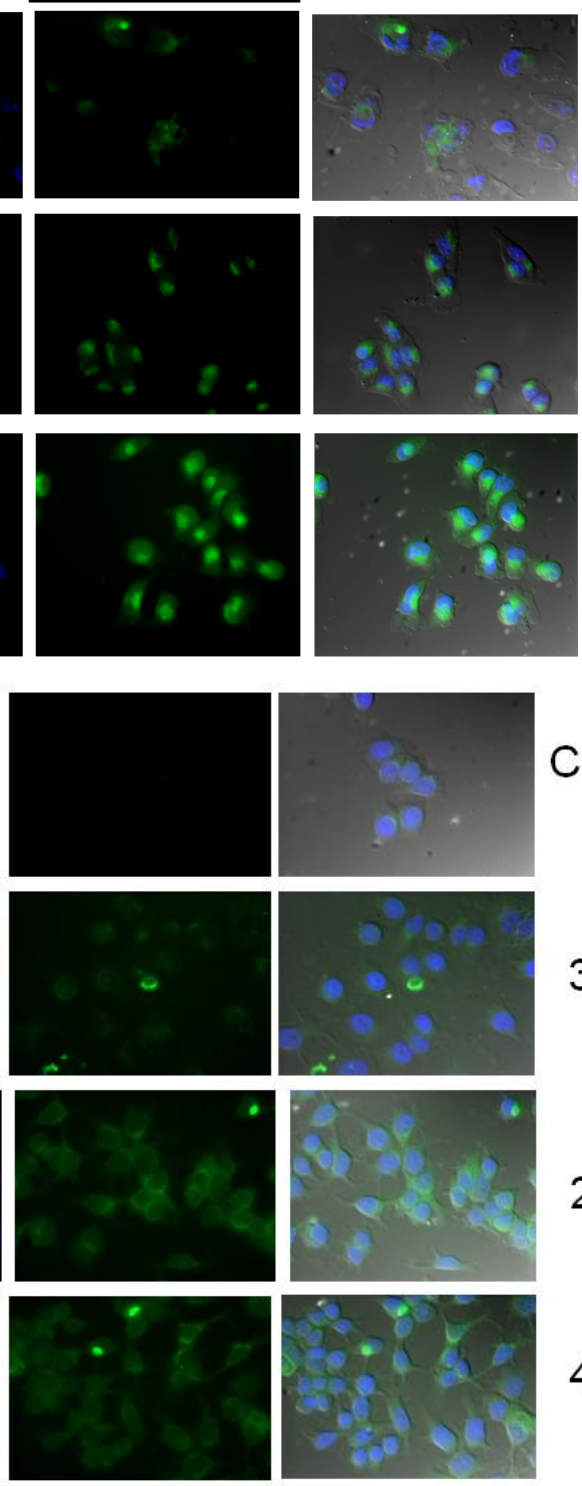

$2 \mathrm{~h}$
$4 \mathrm{~h}$

Control

$30 \mathrm{~min}$
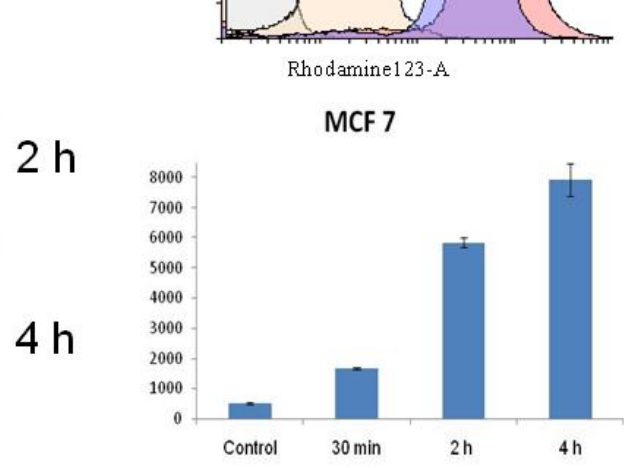

(C)

Figure 2: (A, D) Qualitative analysis indicating the increased cellular uptake with the increase in the Rh-123 intensity for MCF-7 and MDA-MB-231 cells; (B, E) Flow cytometry histogram overlays for MCF-7 and MDA-MB-231 cells of Rh-123 SNELS following $\square 30 \mathrm{~min}, \square 2 \mathrm{~h}$ and $\quad 4 \mathrm{~h}$ incubation at $37^{\circ} \mathrm{C}$ with $\square$ control cells as untreated cells; (C, F) Fluorescence intensity plotted vs time also corroborated the cellular uptake for MCF-7 and MDA-MB-231 cells 

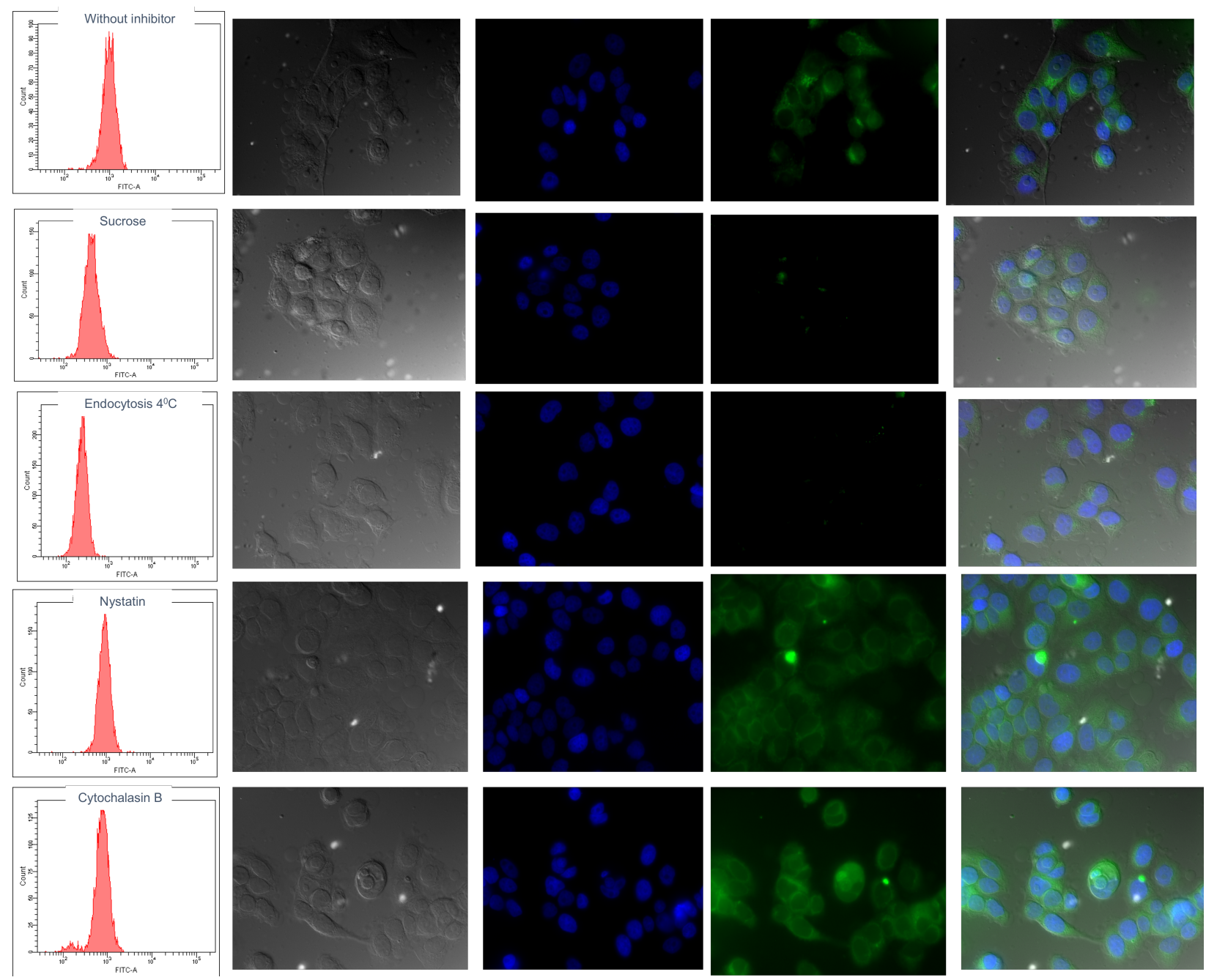

\section{MCF-7}

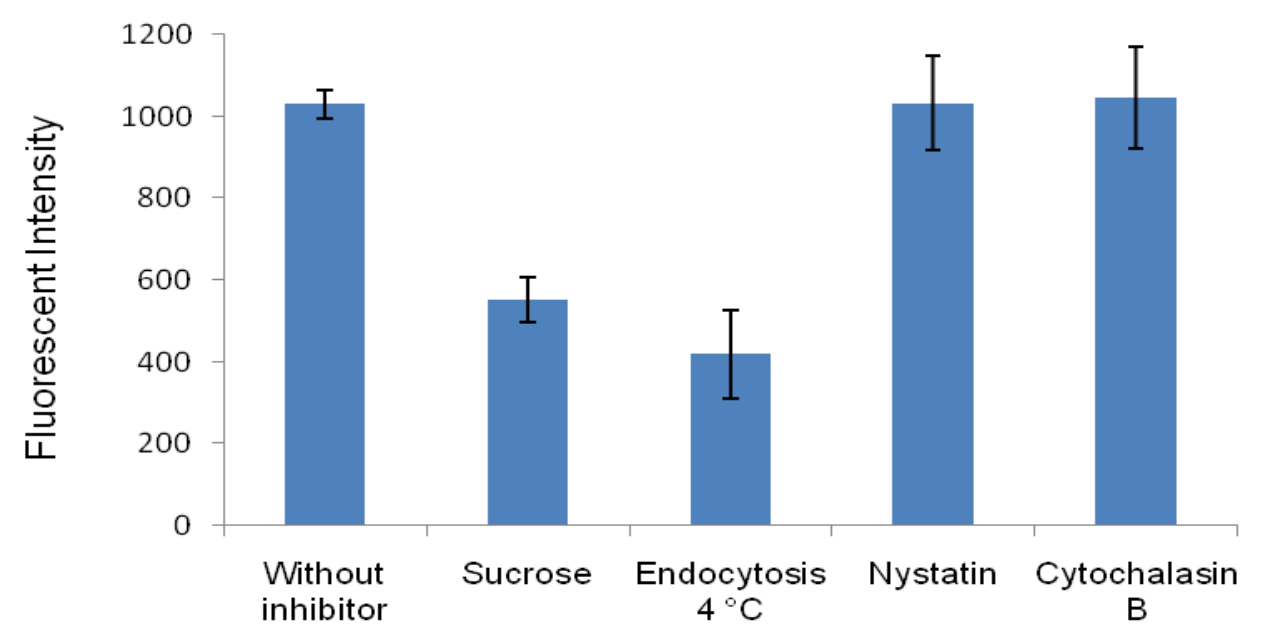




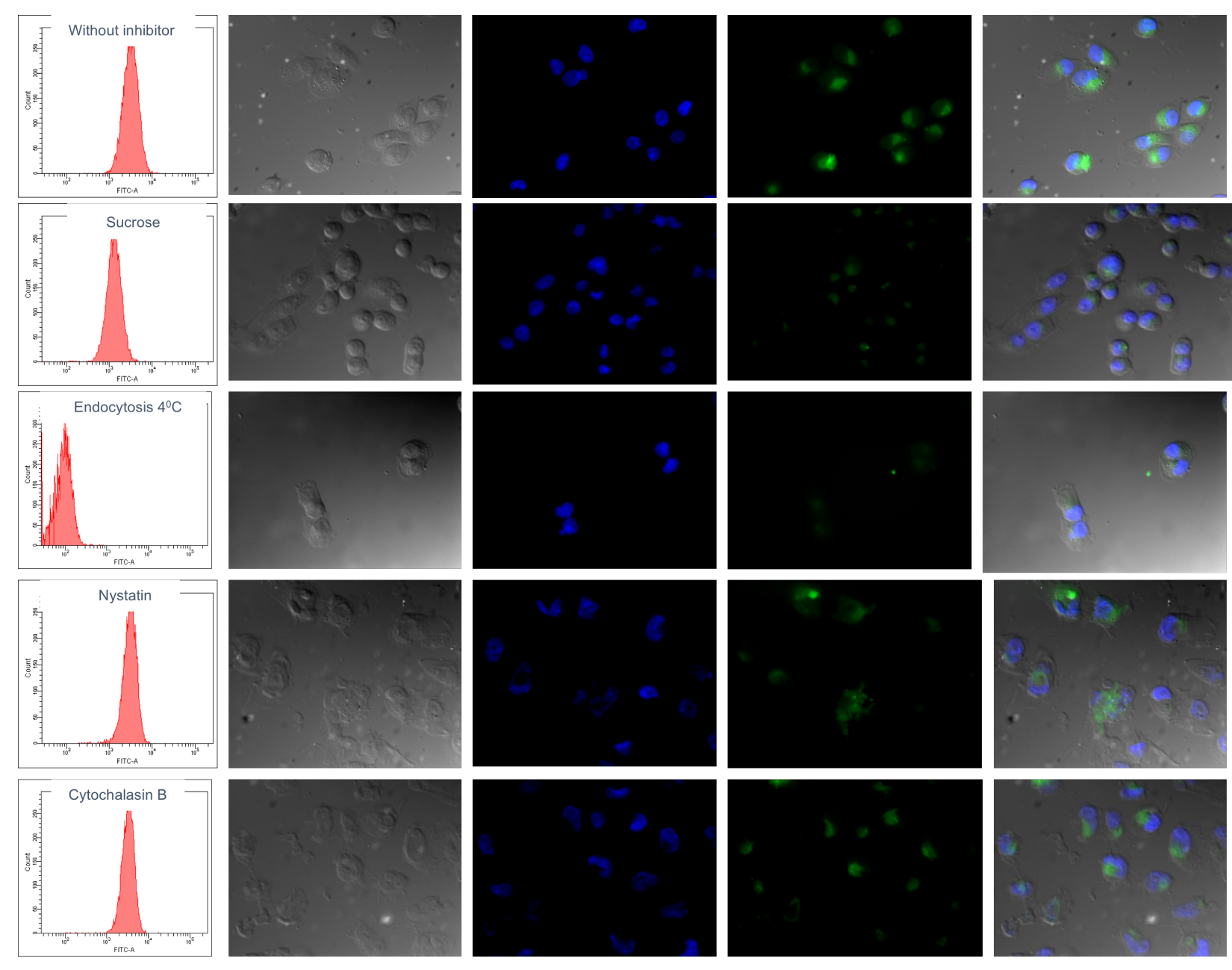

MDA-MB-231

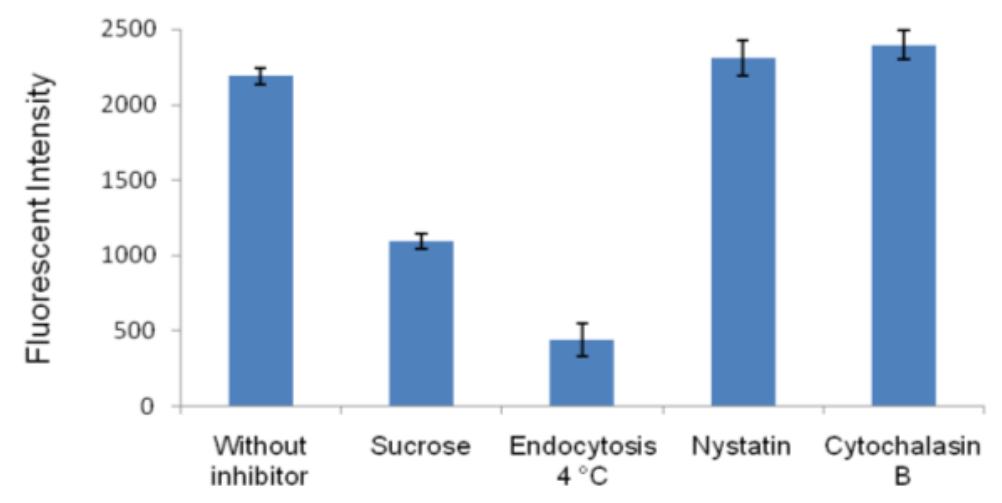

Figure 3: Effect of endocytic inhibitors and low temperature on accumulation of Rh-123 loaded SNELS was measured relative to fluorescent intensity at $30 \mathrm{~min}$, for both, MCF-7 and MDA-MB-231. It is quite evident from the histograms (A and C) and the corresponding fluorescent images that SNELS are majorly being uptaken by the clathrin dependent pathways; Bargraphs (B and D) represent the mean \pm SD $(n=3)$ for the fluorescent intensity obtained after each treatment at different time points, validating the same results. However, precise values also generate very vital information that the uptake of SNELS is by energy dependent pathway. 

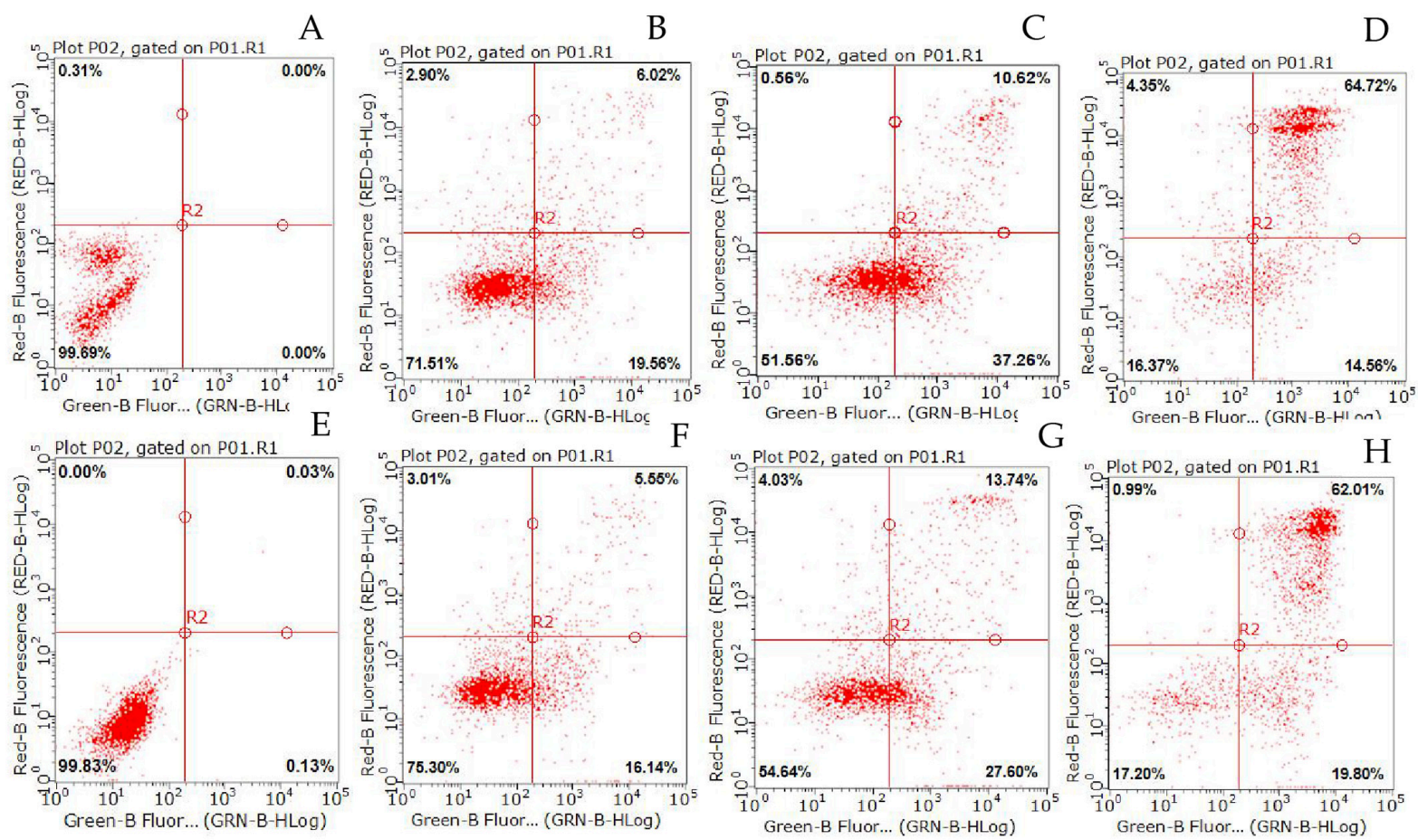

6
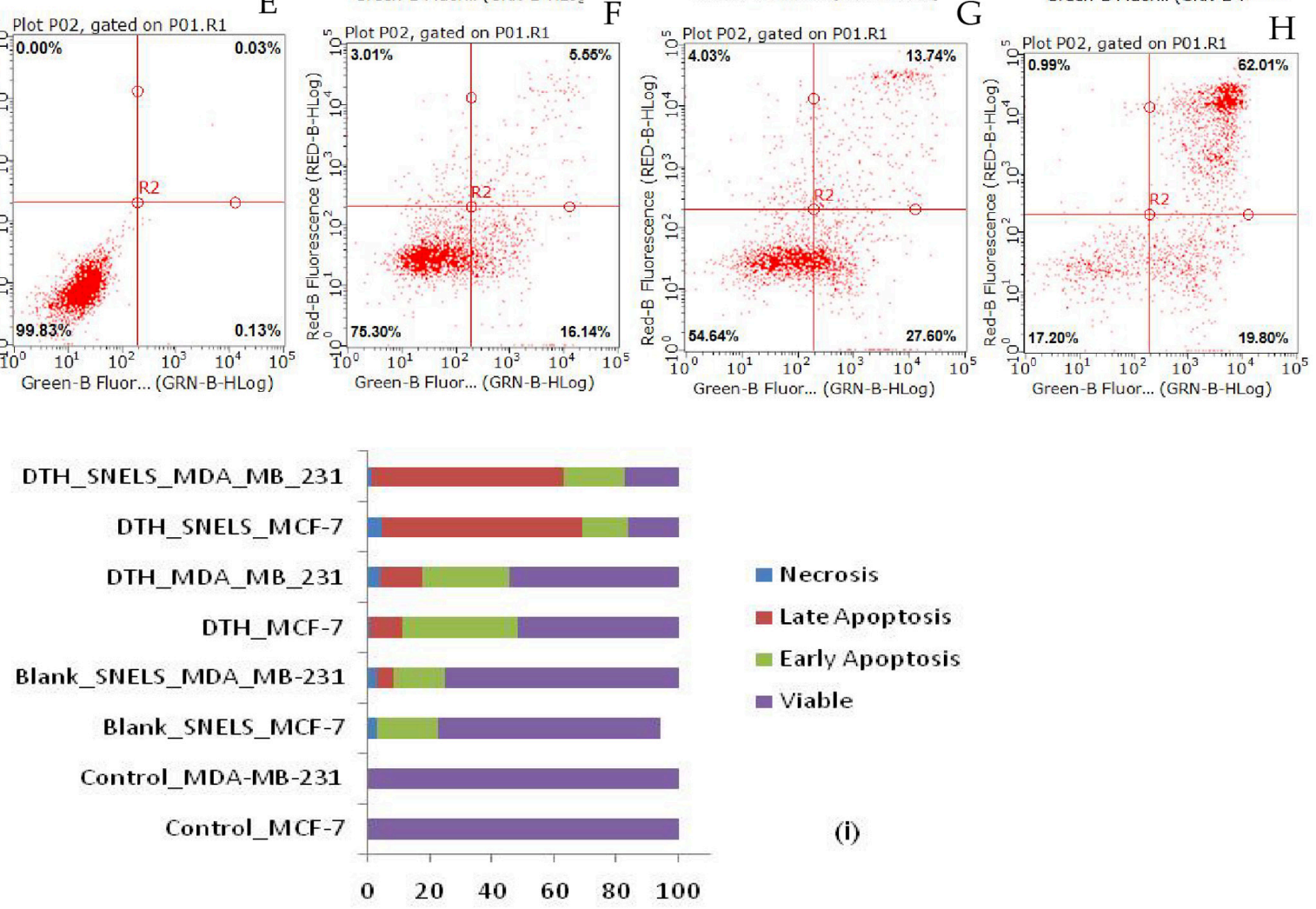

- Necrosis

- Late Apoptosis

Early Apoptosis

viable

(i)

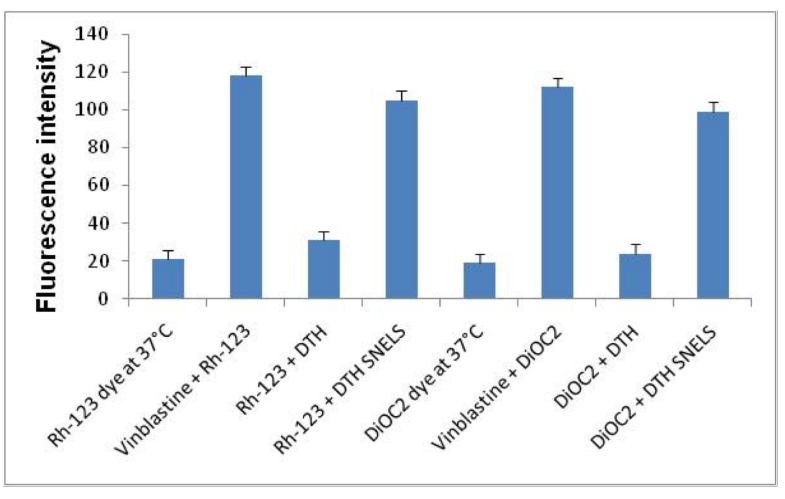

J

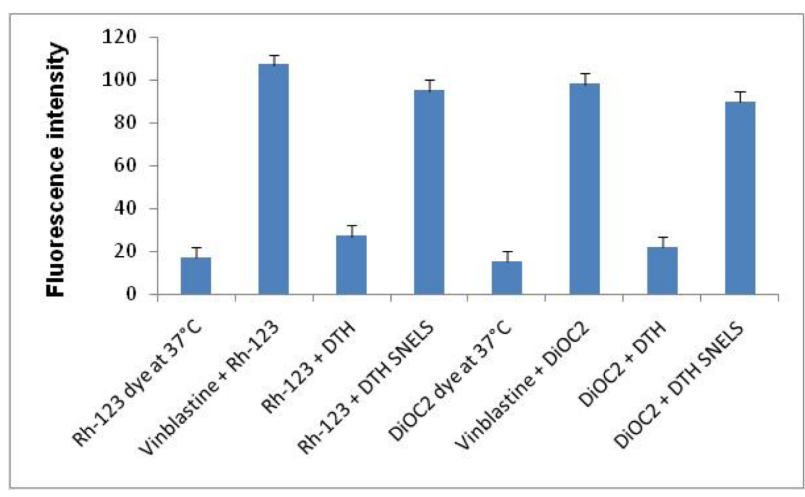

K 


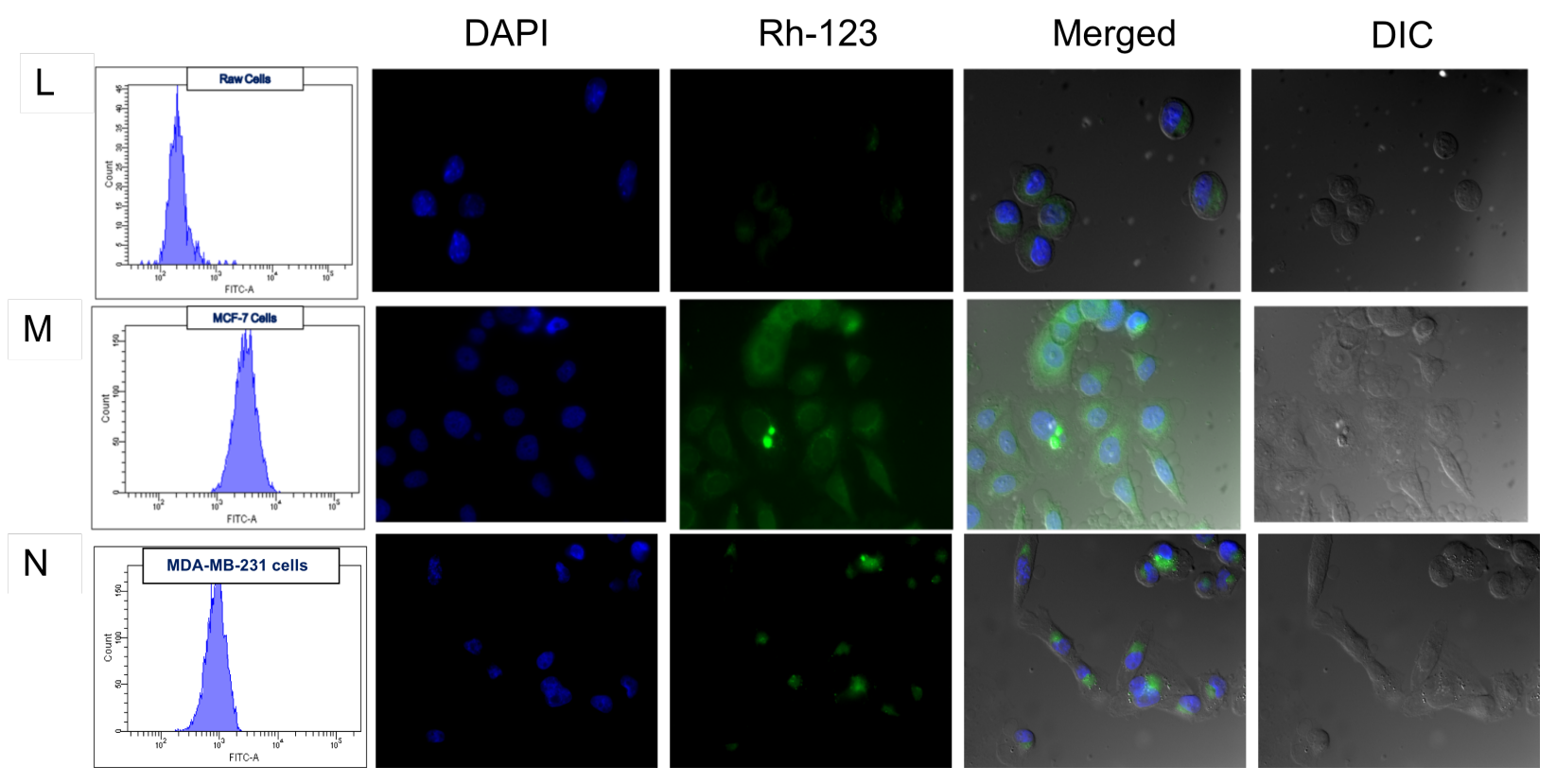

Figure 4: MCF-7: (A) Control, (B) Blank SNELS, (C) DTH, (D) DTH SNELS; MDAMD-231: (E) Control, (F) Blank SNELS, (G) DTH, (H) DTH SNELS; (I) Histogram of necrosis, late apoptosis, early apoptosis and viable cells for both MCF-7 and MDA-MB-231; Effect of DTH SNELS on efflux of MDRI transporter Rh-123 and BCRP transporter DiOC ${ }^{2}$ as measured by fluorescence in (J) MCF-7 and (K) MDAMB-231 cells; Histograms and fluorescent images indicating the extent of cellular uptake in (L) raw, (M) MCF-7 and (N) MDA-MB-231 cells of optimized formulation.
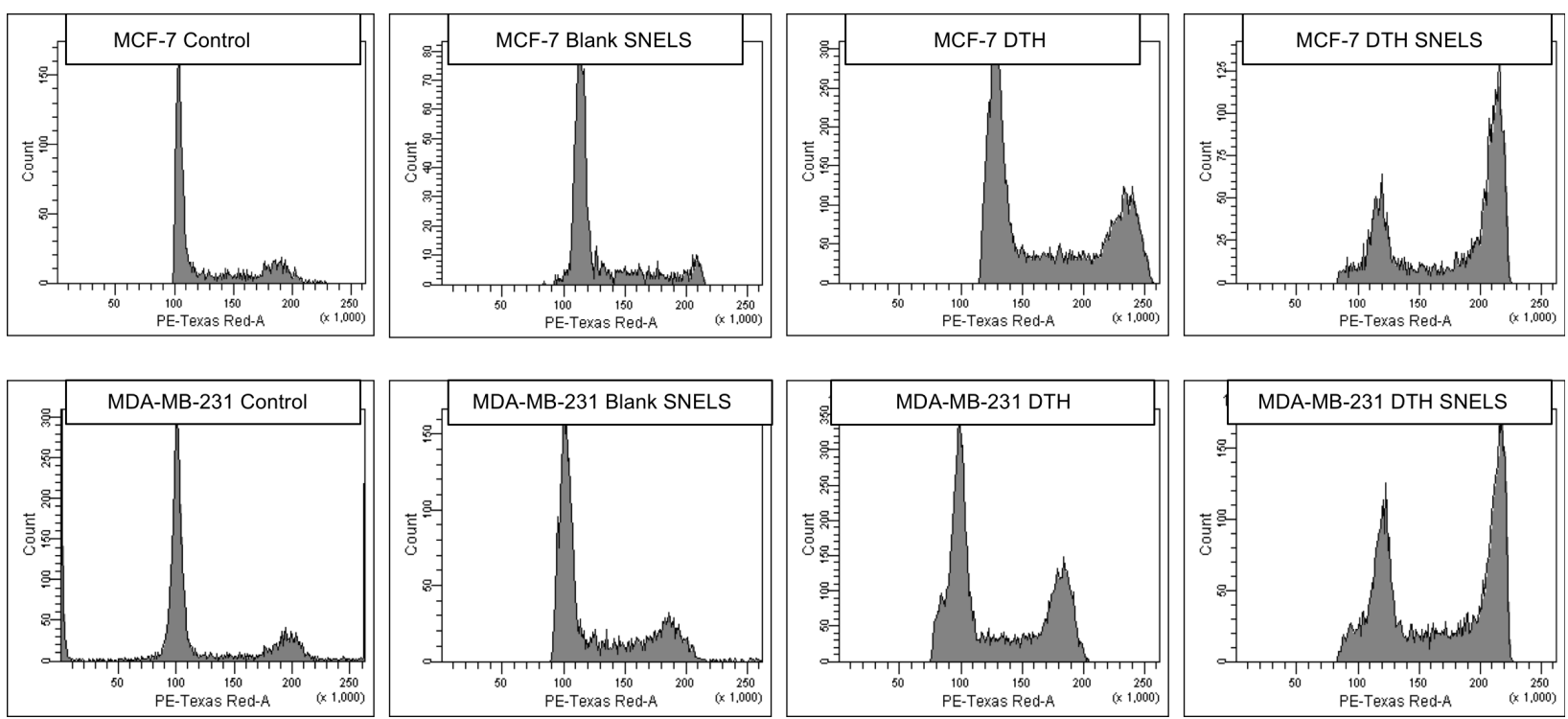

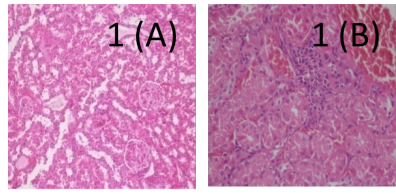

$3(\mathrm{~A})$

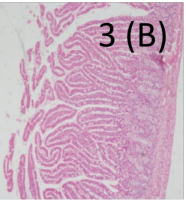

5 (A)

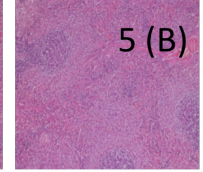

7 (A)
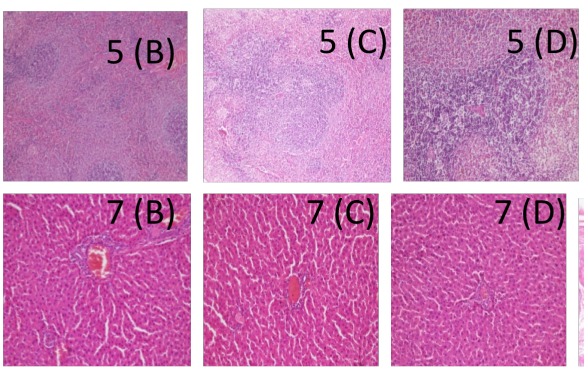

(ii)
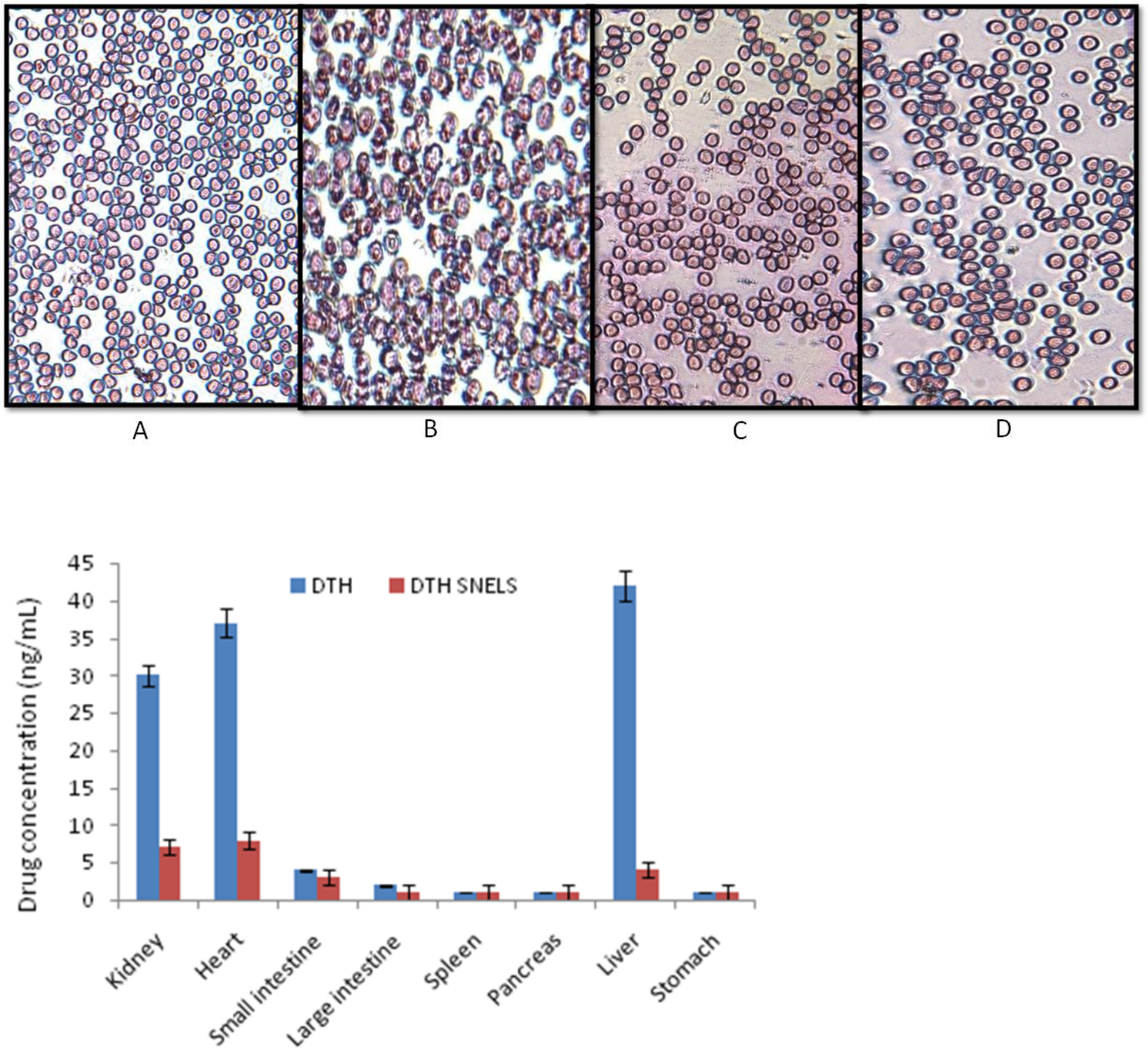
Figure 5: (i) Pictures depicting G2/M phase arrest for both MCF-7 and MDA-MB-231; (ii) Histopathological findings were examined on comparing with the (A) normal rat after administering (B) plain DTH, (C) blank SNELS formulation, (D) DTH-SNELS on various vital organs (1) Kidney; (2) Heart; (3) Small intestine; (4) Large intestine; (5) Spleen; (6) Pancreas; (7) Liver; (8) Stomach. (iii) Haematological pictures of rats when treated as (A) Control (B) DTH (C) Blank SNELS (D) DTH SNELS; (iv) Biodistribution of DTH and DTH SNELS in various body organs of rats
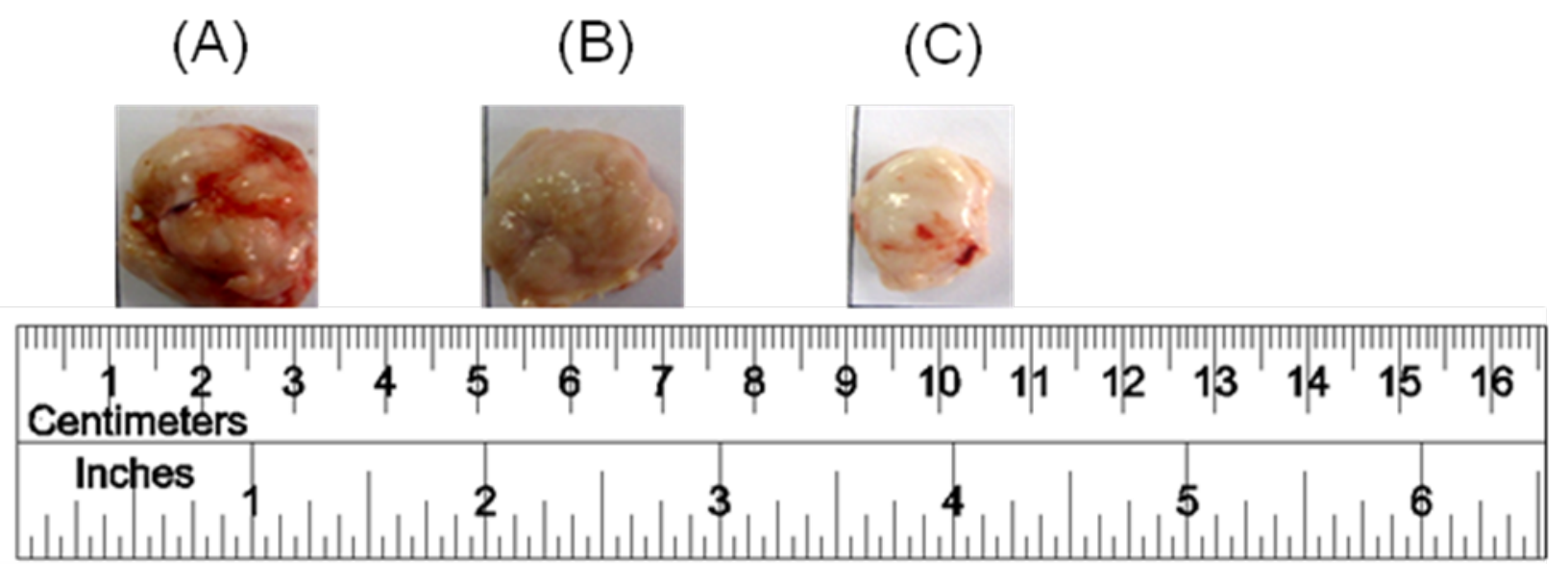

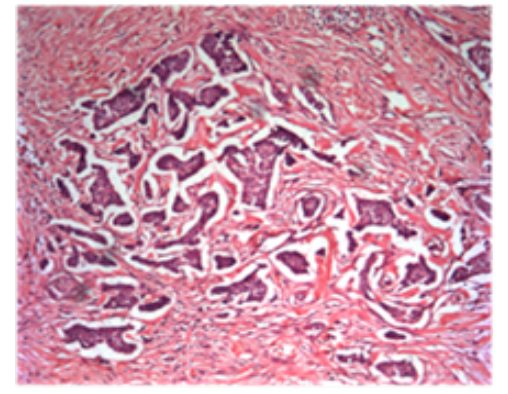

$\mathrm{D}$

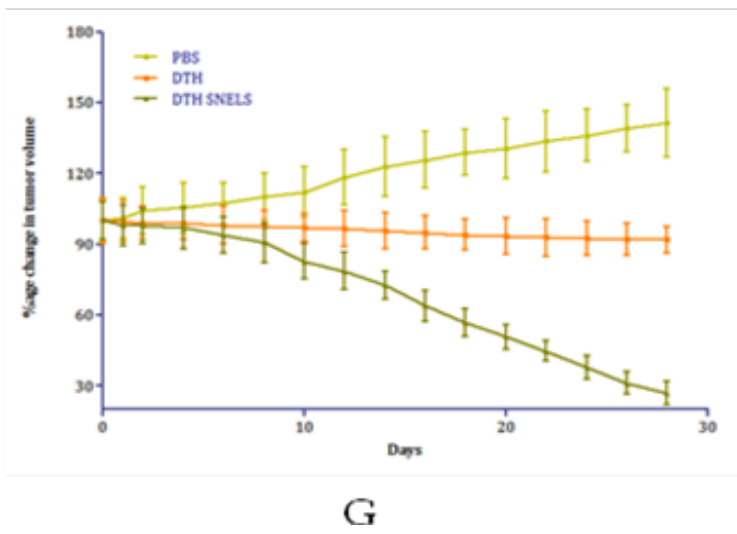

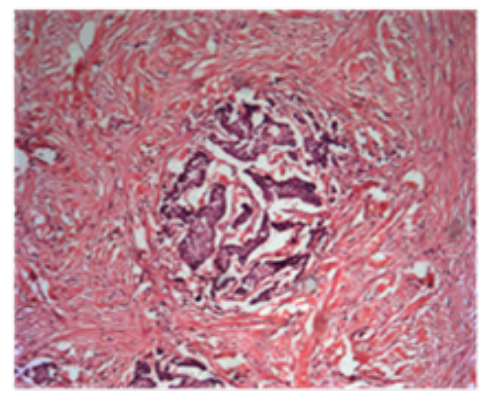

$\mathrm{E}$

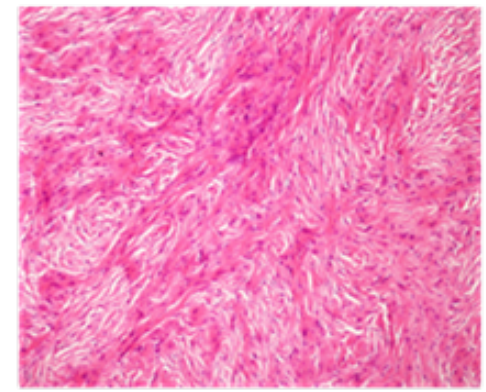

$\mathrm{F}$

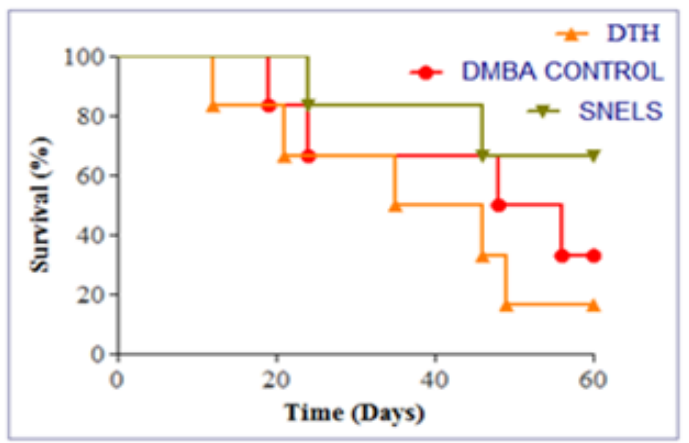

$\mathrm{H}$

Figure 6: In vivo antitumor efficacy of DTH SNELS. Picture of excised tumor tissue (A) Control; (B) DTH ; (C) DTH SNELS ; H\&E stained images (D) Control and (E) Plain DTH: showing an invasive tumor arranged in closely packed clusters surrounded by desmoplastic stromal reaction consistent with invasive mammary carcinoma, (F) $H \& E$ 
sections of DTH SNELS treated rat shows no residual malignancy and only fibrocolagenous tissue. (G) Tumor progression after repetitive oral administration of DTH SNELS (20 mg/kg equivalent to free DTH), DTH (20 mg/kg). (H) Kaplan-Meier survival curve of tumor-bearing rat treated with DTH and DTH SNELS. Tumor volume was taken as $100 \%$ at the start of drug treatment and tumor progression monitored till the end of the study. Each data point is represented as mean $\pm \operatorname{SEM}(n=$ 6).

Table 1: Depicting the various percentages of cells in different cell cycles for various treatments

\begin{tabular}{|l|l|l|l|l|l|l|}
\hline \multirow{2}{*}{ Groups } & MCF-7 & MDA-MB-231 & MCF-7 & MDA-MB-231 & MCF-7 & MDA-MB- \\
\cline { 2 - 7 } & \multicolumn{2}{|c|}{ G0/G1 } & & & & 231 \\
\hline Control & $63.3+2.8$ & $72.5+2.5$ & $20.4+1.3$ & $18.8+1.5$ & $14.1+0.6$ & $7.9+1.2$ \\
\hline $\begin{array}{l}\text { Blank } \\
\text { SNELS }\end{array}$ & $65.3+3.7$ & $70.6+1.7$ & $31.2+2.2$ & $31.0+2.7$ & $14.5+0.9$ & $12.3+1.0$ \\
\hline DTH & $50.1+5.4$ & $48.8+3.4$ & $17.5+1.6$ & $18.9+2.1$ & $19.6+1.2$ & $21.9+2.3$ \\
\hline $\begin{array}{l}\text { DTH } \\
\text { SNELS }\end{array}$ & $40.6+2.7$ & $38.9+1.4$ & $24.7+1.9$ & $23.7+1.9$ & $43.5+1.1$ & $47.5+3.1$ \\
\hline
\end{tabular}

*SD: mean \pm 3

Table 2: Whole blood count parameters

\begin{tabular}{|c|c|c|c|c|}
\hline \multirow{2}{*}{ Mode } & Control & DTH & Blank SNELS & DTH SNELS \\
\cline { 2 - 5 } & Count & Count & Count & Count \\
\hline WBC & $22.9 \times 10^{3} / \mu \mathrm{L}$ & $6.6 \times 10^{3} / \mu \mathrm{L}$ & $21.7 \times 10^{3} / \mu \mathrm{L}$ & $15.9 \times 10^{3} / \mu \mathrm{L}$ \\
\hline RBC & $9.95 \times 10^{6} / \mu \mathrm{L}$ & $7.10 \times 10^{6} / \mu \mathrm{L}$ & $8.32 \times 10^{6} / \mu \mathrm{L}$ & $8.18 \times 10^{6} / \mu \mathrm{L}$ \\
\hline HGB & $16.1 \mathrm{~g} / \mathrm{dL}$ & $12.5 \mathrm{~g} / \mathrm{dL}$ & $15.8 \mathrm{~g} / \mathrm{dL}$ & $14.8 \mathrm{~g} / \mathrm{dL}$ \\
\hline HCT & $49.8 \%$ & $38.6 \%$ & $46.7 \%$ & $40.1 \%$ \\
\hline PLT & $\mathrm{AG} * 880 \times$ & $\mathrm{AG}^{*} 277 \times 10^{3} / \mu \mathrm{L}$ & $\mathrm{AG}^{*} 812 \times 10^{3} / \mu \mathrm{L}$ & $\mathrm{AG} * 40 \mathrm{x}$ \\
& $103 / \mu \mathrm{L}$ & & & $10^{3} / \mu \mathrm{L}$ \\
\hline
\end{tabular}

- $\mathrm{SD}$ mean \pm 3 


\section{SUPPLEMANTARY MATERIAL}

\section{Section 1: Brief preparation and optimisation of DTH-SNELS}

Lipidic systems facilitate the dissolution of poorly soluble drugs with moderate $\log \mathrm{P}$, and tend to augment oral biopharmaceutical performance by circumventing first-pass effect and enhancing lymphatic uptake too.

The current studies, therefore are the extension of the earlier reported work in which the SNELS of DTH with varied lipidic chain length were developed by applying Quality by Design (QbD) approach, in order to augment the oral absorption and intestinal permeability of DTH.

In lieu of the development, Placket Burman Design suggested that while preparing SNELS, oils, emulgents and co-emulgents are the most influential critical quality materials (CQMs). Equilibrium solubility studies revealed that maximum solubility of DTH was found in Maisine-35-1 and Capmul MCM (lipids), Tween 80 (nonionic emulgent) and Transcutol HP (co-emulgent). Further, D- and Ioptimal mixture designs were employed to obtain the optimal formulations. Various critical quality attributes (CQAs) were "traded off" to attain the desired objectives, i.e., smaller globule size $\left(\mathrm{D}_{\mathrm{nm}}\right)$, minimum emulsification time $\left(\mathrm{T}_{\mathrm{emul}}\right)$, with maximum release in $15 \mathrm{~min}\left(\mathrm{Rel}_{15 \mathrm{~min}}\right)$ and higher permeability in 45 min $\left(\right.$ Perm $\left._{45 \mathrm{~min}}\right)$. In order to attain the stated objectives, the selection criteria embarked upon to search the optimized formulation were $T_{\text {emul }}<5$ min, $D_{n m}<100 \mathrm{~nm}$ and $\operatorname{Rel}_{15 \min }>80 \%$. Numerical optimization methodology was carried out for identifying the optimum formulation, where all the CQAs exhibited desirability close to unity.

The optimum DTH-SNELS contained Maisine-35-1 (338 mg), Tween 80 (434 mg) and Transcutol HP (227 mg), with the values of CQAs as $\mathrm{D}_{\mathrm{nm}}$ of $98 \mathrm{~nm}, \mathrm{~T}_{\mathrm{emul}}$ of $1.3 \mathrm{~min}, \mathrm{Rel}_{15 \mathrm{~min}}$ of $75 \%$ and $\mathrm{Perm}_{45 \mathrm{~min}}$ $82 \%$.. The developed DTH SNELS formulations were further extensively characterized.

\section{Supplementary Section 2: Characterization of DTH-SNELS}

2.1 Self-emulsification time: One gram of optimized DTH-SNELS were prepared and added to 250 $\mathrm{mL}$ of $0.1 \mathrm{~N} \mathrm{HCl}(\mathrm{pH} 1.2)$ under continuous stirring (50 rpm) using a USP XXXI Apparatus II (DS $8000, \mathrm{M} / \mathrm{s}$ Labindia Instruments, Mumbai, India) at $37 \pm 0.5{ }^{\circ} \mathrm{C}$. The time required for complete dispersion of the formulation in aqueous phase to form nanoemulsion was recorded as selfemulsification time. 
2.2 Globule size and zeta potential: Aliquots of $1 \mathrm{~mL}$ each of the diluted DTH-SNELS were subjected for globule size analysis and zeta potential measurement employing dynamic light scattering technique (Zetasizer ZS 90, M/s Malvern Instruments, Worcestershire, UK).

2.3 Transmission electron microscopy (TEM)

Optimized DTH-SNELS formulation was diluted and subsequently stained with 1\% phosphotungstic acid for $1 \mathrm{~min}$, before subjecting for TEM analysis (JEM-2100 F, M/s Jeol, Tokyo, Japan).

TEM imaging of optimized SNELS, comprising of Maisine-35-1 revealed the size range between 60.4 and $70.7 \mathrm{~nm}$

\section{Supplementary Section 3: MCF-7 and MDA-MB-231 Cell Culture Experiments}

The MCF-7 cell lines were obtained from University of Manchester, UK while MDA-MB-231 cell lines were purchased from ECACC, Public Health England, Salisbury, England. MCF-7 cell lines were grown in tissue culture flasks $\left(75 \mathrm{~cm}^{2}\right)$ and maintained under $5 \% \mathrm{CO}_{2}$ atmosphere at $37{ }^{\circ} \mathrm{C}$. The growth medium comprised of Dulbecco's Modified Eagle's Medium (DMEM, Sigma). The cultured cells were trypsinized once $90 \%$ confluent with $1 \%$ trypsin. Similarly, MDA-MB-231 cells were grown in L-15 Medium (Leibovitz) media.

\subsection{Cell Viability Assay}

Briefly, $1 \times 10^{3}$ cells in $100 \mu \mathrm{L}$ per well in 96-well culture plate (Costars, Corning Inc., NY, USA) were seeded and incubated for $24 \mathrm{~h}$. The medium was replaced with $90 \mu \mathrm{L}$ of medium containing different concentrations (10-1000 nM) of DTH or SNELS containing an equivalent amount of DTH. Cells were treated for 24,48 and $72 \mathrm{~h}$ in separate culture plates and $10 \mu \mathrm{L}$ of PrestoBlue was added 1 $\mathrm{h}$ before each of the respective time interval. Cell viability was calculated using fluorescence measurement at $560 \mathrm{~nm}$ excitation and $590 \mathrm{~nm}$ emission wavelength, and expressed as percentage normalized to untreated controlled cells.

\subsection{P-gp Efflux Studies}

For evaluating the P-gp efflux, the multi-drug resistance dye efflux assay kit (M/s Chemicon International, USA) was employed. The efflux activity was measured to determine the intracellular accumulation of the fluorescent dyes, Rh-123 and $\mathrm{DiOC}_{2}$, to access the inhibitory activity of SNELS on MDR1 and BCRP transporters, respectively. MCF-7 and MDA-MB-231 containing $2.5 \times 10^{5}$ cells were incubated with Rh-123 alone, Rh-123 and vinblastine, Rh-123 loaded DTH-SNELS for $2 \mathrm{~h}$ at 
$37^{\circ} \mathrm{C}$. All the formulations were suspended in RPMI-1640 medium (M/s Sigma-Aldrich, UK). Likewise, to estimate the potential of the developed SNELS formulation for blocking the activity of BCRP transporters, DiOC $_{2}$ dye was employed. Similarly, MCF-7 and MDA-MB-231 $\left(2.5 \times 10^{5}\right)$ cells were incubated with $\mathrm{DiOC}_{2}$ alone, $\mathrm{DiOC}_{2}$ and vinblastine, $\mathrm{DiOC}_{2}$ loaded DTH-SNELS for $2 \mathrm{~h}$ at 37 ${ }^{\circ} \mathrm{C}$. The cells were washed with pre-warmed PBS and the fluorescence intensity was measured in a TECAN fluorescence microplate reader at an excitation wavelength of $485 \mathrm{~nm}$ and an emission wavelength of $530 \mathrm{~nm}$.

\section{Supplementary Section 4}

A total of 12 Sprague Dawley (SD) female rats were divided into four groups of animals ( $\mathrm{n}=3 \mathrm{each}$ ). Standard housing conditions were maintained and animals were allowed for regular solid feed and water ad-libitum. Free DTH, DTH-loaded and blank SNELS were administered by oral gavage at dose of $20 \mathrm{mg} / \mathrm{kg}$ (equivalent of DTH), thrice a week for a total period of 4 weeks. Animals of control group were administered with normal saline. At the end of treatment in all groups, blood samples were collected using cardiac puncture, and animals were euthanized using diethyl ether. Haematological analysis was performed on blood samples and complete blood count and haemoglobin content (\%) were measured. Also DTH levels in blood plasma were estimated by a previously reported method by our group.

Afterwards, the animals were sacrificed using cervical dislocation procedure and vital organs (i.e., kidney, heart, small intestine, large intestine, spleen, pancreas, liver and stomach were carefully isolated with the help of surgical scissors. The organs were kept in petriplate and thoroughly washed with ice cold PBS ( $\mathrm{pH}$ 7.4) to remove the cellular debris. Further, the organs were minced and crushed in a tissue homogenizer. The tissue homogenates were subjected to centrifugation at 5,000 rpm $(1,118 \times \mathrm{g})$ and supernatant was collected for extraction of the drug by liquid-liquid extraction process using acetonitrile as the extracting solvent. The samples were filtered and subsequently analyzed employing a previously developed and validated UPLC method of DTH for analyzing drug concentration in various organs.

All the vital organs were collected from all the groups, fixed in $10 \%$ formalin in saline, dehydrated in ascending grades of ethyl alcohol, cleared in xylol and mounted in molten paraplast at $58-62^{\circ} \mathrm{C}$. Sections of $5 \mu \mathrm{m}$ thickness were obtained on poly-L-lysin pre-coated slides and were stained using hematoxilin and eosin. Slides were evaluated for any structural change(s) under an upright light microscope (Olympus, Tokyo, Japan). 
Table S1: IC50 Values DTH, blank and DTH SNELS at 24, 48 h, $72 \mathrm{~h}$ in MCF-7 and MDA-MB-231 cells

\begin{tabular}{|c|c|c|c|}
\hline \multicolumn{4}{|c|}{ IC $_{50}$ MCF-7 Cells (nM) } \\
\hline & $24 \mathrm{~h}$ & $48 \mathrm{~h}$ & $72 \mathrm{~h}$ \\
\hline$\overline{\mathrm{DTH}}$ & 25.38 & 12.23 & 9.99 \\
\hline BLANK SNELS & 121.50 & 95.66 & 81.20 \\
\hline DTH SNELS & 5.39 & 2.05 & 1.15 \\
\hline \multicolumn{4}{|c|}{ IC $_{50}$ MDA-MB-231 Cells (nM) } \\
\hline DTH & 185.61 & 165.25 & 154.29 \\
\hline BLANK SNELS & 122.10 & 97.63 & 52.10 \\
\hline DTH SNELS & 98.97 & 78.97 & 45.95 \\
\hline
\end{tabular}

Data shown here is Mean \pm SD from 3 independent experiments. 